\title{
On the Moisture Origins of Tornadic Thunderstorms
}

\author{
Maria J. Molina And John T. Allen \\ Department of Earth and Atmospheric Sciences, Central Michigan University, Mount Pleasant, Michigan
}

(Manuscript received 14 November 2018, in final form 12 April 2019)

\begin{abstract}
Tornadic thunderstorms rely on the availability of sufficient low-level moisture, but the source regions of that moisture have not been explicitly demarcated. Using the NOAA Air Resources Laboratory HYSPLIT model and a Lagrangian-based diagnostic, moisture attribution was conducted to identify the moisture source regions of tornadic convection. This study reveals a seasonal cycle in the origins and advection patterns of water vapor contributing to winter and spring tornado-producing storms (1981-2017). The Gulf of Mexico is shown to be the predominant source of moisture during both winter and spring, making up more than $50 \%$ of all contributions. During winter, substantial moisture contributions for tornadic convection also emanate from the western Caribbean Sea $(>19 \%)$ and North Atlantic Ocean $(>12 \%)$. During late spring, land areas (e.g., soil and vegetation) of the contiguous United States (CONUS) play a more influential role $(>24 \%)$. Moisture attribution was also conducted for nontornadic cases and tornado outbreaks. Findings show that moisture sources of nontornadic events are more proximal to the CONUS than moisture sources of tornado outbreaks. Oceanic influences on the water vapor content of air parcels were also explored to determine if they can increase the likelihood of an air mass attaining moisture that will eventually contribute to severe thunderstorms. Warmer sea surface temperatures were generally found to enhance evaporative fluxes of overlying air parcels. The influence of atmospheric features on synoptic-scale moisture advection was also analyzed; stronger extratropical cyclones and Great Plains low-level jet occurrences lead to increased meridional moisture flux.
\end{abstract}

\section{Introduction}

Boundary layer moisture is vital for tornadic thunderstorm development (Galway 1979; Hagemeyer 1991; Doswell et al. 1996). Therefore, identifying the source regions and processes governing moisture advection can improve our understanding of the physical drivers responsible for their occurrence. Operational forecasters and researchers have recognized the Gulf of Mexico (GoM) as an important source of moisture for tornadic storms in the contiguous United States (CONUS) for several decades (Lewis et al. 1989; Edwards and Weiss 1996; Brooks et al. 2003; Jung and Kirtman 2016; Molina et al. 2016, 2018; Childs et al. 2018). Prior research has identified a statistical relationship between warm sea surface temperatures (SSTs) of the Loop Current (LC; Vukovich 2007) across the eastern GoM and tornado frequency (Molina et al. 2016), but this approach failed to quantify water vapor contributions from the LC region. Moreover, several studies have suggested linkages

Corresponding author: Maria J. Molina, maria.janet.molina@ gmail.com to other bodies of water, such as the Caribbean Sea (CARIB) and North Atlantic Ocean (NATL; Rasmusson 1967; Gimeno et al. 2012; Elsner and Widen 2014; Lee et al. 2016). The average residence time of water vapor in the atmosphere-from evaporation to precipitation-was estimated to be 4-5 days, with moisture capable of traveling thousands of kilometers before precipitation takes place (Läderach and Sodemann 2016). Thus, it is physically plausible that moisture for hazardous convection over the CONUS is advected from regions beyond the GoM basin. Given the uncertainty regarding moisture sources of convection, this study aims to advance our knowledge of the synoptic-scale hydrological cycle as it relates to tornadic convective storms.

Earlier studies have shown that the GoM can modify the water vapor content of air advected to the CONUS. Hastenrath (1966) determined that air traversing over the GoM acquired water vapor during the winter of 1960, made evident by more evaporation than precipitation along its advection path. A simple Lagrangian trajectory model was used by Molinari (1987) to track air parcels advected over the LC, revealing that the 
specific humidity $q\left(\mathrm{~g} \mathrm{~kg}^{-1}\right)$ of an air parcel was greater when traversing over a deeper LC intrusion (February 1975) than during a shallower LC intrusion (February 1976). While these studies (Hastenrath 1966; Molinari 1987) broadened our understanding of GoM influences on boundary layer moisture, they failed to quantitatively demarcate source regions of evaporation, and faced observational and temporal scope constraints.

Past work has also estimated water vapor budgets in terms of moisture flux divergence using vertically integrated moisture flux (e.g., Rasmusson 1967, 1971; Mestas-Nuñez et al. 2005, 2007). Collectively, these studies have shown meridional moisture advection to the CONUS from the GoM and CARIB regions. Vertically integrated moisture flux $Q$ is computed as

$$
Q=\int_{\text {top }}^{\text {sfc }} \frac{1}{g} q \mathbf{V} d p
$$

where $g$ is gravity, $\mathbf{V}$ is the air parcel velocity vector, and $d p$ is the change in pressure from the surface to the top of the troposphere (Rasmusson 1967; Trenberth 1997). The $Q$ fields provide valuable information in regard to the transport of moisture, but do not explicitly track air masses. Another study used $750-\mathrm{hPa}$ streamlines to estimate the advection of moisture (Hagemeyer 1991), but streamlines only coincide with air parcel trajectories when the local rate of change of velocity is constant (Holton and Hakim 2012), an unrealistic assumption in the days preceding severe thunderstorms because airmass fields respond with greater velocity as synoptic systems approach (Doswell and Bosart 2001; Hawcroft et al. 2012).

Since the work of Molinari (1987), Lagrangian trajectory modeling has evolved to a well-established method to determine the origins of air masses (e.g., Sjostrom and Welker 2009; Kurita 2011; Jana et al. 2018). Trajectory modeling involves the tracing of air parcels back in time and space using a moving frame of reference (Stein et al. 2015). However, a trajectory path alone does not provide information in regard to the locations where evaporation occurred that eventually contributed to the meteorological event. A Lagrangian framework for moisture attribution was introduced by Sodemann et al. (2008) that allows for the quantitative demarcation of meteorological event moisture sources and has since been employed by numerous studies (e.g., Pfahl et al. 2014; Bohlinger et al. 2017).

Using an air parcel trajectory model (Stein et al. 2015) and the Sodemann et al. (2008) moisture attribution algorithm, this study introduces a climatological dataset (1981-2017) to explore the origins of - and physical processes driving advection of-water vapor contributing to tornado events. The climatological data will be used to address the following overarching questions:

1) What are the source regions and advection paths of moisture preceding tornadic convective events?

2) Tornadoes exhibit a seasonal cycle (e.g., Brooks et al. 2007); are water vapor origins and transport patterns also characterized by a seasonal cycle?

3) How do moisture origins and transport patterns of tornadic events differ from nontornadic events? Do they differ from tornado outbreaks?

4) Do moisture sources demonstrate a relationship with atmospheric and oceanic influences, such as SSTs, extratropical cyclones (ETCs), and the Great Plains low-level jet (GPLLJ)?

This study will focus on tornadoes during the winter (December-February (DJF)] and spring [March-May (MAM)] seasons, which are the two deadliest seasons for tornadic activity across the CONUS (Molina et al. 2018).

The climatological characteristics of DJF and MAM tornadoes have differences that are largely related to the seasonal cycle. DJF is characterized by the southward protrusion of the meridionally oriented polar jet across the CONUS, which leads to a reduction in low-level moisture return due to cold air advection upstream of ETCs (Lewis et al. 1989; Sherburn and Parker 2014; Allen et al. 2015; King et al. 2017). As a result, tornado frequency is lower in DJF as compared to other seasons (Molina et al. 2018), primarily favored across the southeastern CONUS and generally independent of the diurnal cycle (Sherburn et al. 2016; Childs et al. 2018; Krocak and Brooks 2018). In contrast, MAM is characterized by increased shortwave radiation and a northward retreat of the polar jet, which helps transport moisture farther north and increases near-surface air parcel buoyancy (Rasmussen and Blanchard 1998; Smith et al. 2012; Thompson et al. 2012; Molina et al. 2016). Greater low-level moisture availability during MAM can provide a favorable atmospheric environment for thunderstorm initiation and sustainment, if coupled with a favorable kinematic profile and vertical forcing (Doswell et al. 1996). Consequently, tornadic activity is more climatologically likely during MAM, with geographical coverage expanding north and west of the southeastern CONUS as the season evolves (Brooks et al. 2003). However, convection relies on many environmental factors, with large-scale dynamics, kinematics, and mesoscale thermodynamics working simultaneously to create favorable or unfavorable conditions for tornado formation (Doswell 1987). We will focus on features that influence evaporative fluxes and overall wind flow preceding tornadic thunderstorms in 
order to broaden the understanding of the physical mechanisms driving the origins and advection of moisture contributions.

\section{Data and methods}

\section{a. Air parcel backward trajectories}

The first step in identifying the moisture sources of tornadic storms involves modeling the advection paths of air parcels back in time and space. These air parcel paths are referred to as backward trajectories and were generated using the National Oceanic and Atmospheric Administration (NOAA) Air Resources Laboratory (ARL) Hybrid Single-Particle Lagrangian Integrated Trajectory model (HYSPLIT; Stein et al. 2015). HYSPLIT was run using data from the North American Regional Reanalysis (NARR; Mesinger et al. 2006) in ARL format. ${ }^{1}$ NARR was chosen because its domain extends beyond the GoM basin and is of sufficient temporal and spatial resolution to capture intraday variability of air parcels (3-hourly temporal, 32-km grid spacing, and 24 vertical layers). HYSPLIT calculates backward trajectories by averaging air parcel 3D velocity vectors at initial and first guess positions iteratively through the predetermined trajectory run time (Draxler et al. 2016). A backward-trajectory run time of $120 \mathrm{~h}$ was chosen for this experiment, with the reasoning being twofold: (i) moisture residence time in the troposphere is generally less than $120 \mathrm{~h}$ (Läderach and Sodemann 2016) and (ii) $120 \mathrm{~h}$ allowed for air parcel trajectory characterization beyond the GoM basin, while generally remaining within the available spatial domain for NARR. Trajectories that exited the NARR domain prior to a backward-trajectory analysis of $120 \mathrm{~h}$ were terminated upon exit.

Backward trajectories were initialized from DJF and MAM tornado occurrences across the CONUS. The most comprehensive dataset of severe weather events over the CONUS is NOAA's Storm Prediction Center (SPC) severe event archive (Schaefer and Edwards 1999) and it was therefore utilized as a reference for past tornado occurrences. The SPC severe event archive contains the latitude, longitude, and approximate genesis time of past tornadoes, which were used to initiate HYSPLIT air parcel releases (e.g., Fig. 1). The SPC severe event database does contain long-term trends and limitations of nonmeteorological origin, including population biases and rating inconsistencies, as

\footnotetext{
${ }^{1}$ NARR data in ARL format are freely available at https:// www.ready.noaa.gov/archives.php.
}

thoroughly discussed in prior studies (e.g., Verbout et al. 2006; Doswell et al. 2009; Edwards et al. 2013; Brooks et al. 2014). An established method to mitigate SPC severe event archive issues is to omit tornadoes rated EF0 (rated using the enhanced Fujita scale; Fujita 1971; McDonald and Mehta 2006) from climatological analyses (e.g., Verbout et al. 2006; Lee et al. 2016; Childs et al. 2018), given that EF1+ and "significant tornadoes" (consisting of EF2 + herein) exhibit greater consistency in the record and no statistically significant trends on a continental aggregate (Schaefer et al. 2002; Brooks et al. 2014). Trajectories were accordingly generated for tornadoes of EF1+ and significant intensity from the period 1981-2017, which matches the temporal range of SST data (Reynolds et al. 2007) used for a subsequent statistical analysis in this study.

Trajectory modeling is sensitive to minor spatial adjustments during initiation, which can result in discernibly different trajectories, even when trajectories are initiated within the same meteorological model grid cell (Stohl 1998). In an effort to ameliorate trajectory modeling sensitivity and akin to prior studies (e.g., Gustafsson et al. 2010; De Leeuw et al. 2017), 3D trajectory matrices were used for each tornado report in lieu of singular trajectories, each composed of 1331 backward trajectories. Trajectory matrices were centered at each tornado report's origin coordinate (latitude, longitude), initiation hour, and planetary boundary layer height (HPBL; m). All vertical heights herein are above ground level (AGL). HPBL is a NARR output variable, calculated from a diagnostic equation that uses turbulent kinetic energy (Janjić 1996), and has been found comparable in skill to other modeled HPBL (e.g., Angevine and Mitchell 2001; Schmid and Niyogi 2012). Every horizontal plane of a trajectory matrix contained 121 trajectories spaced at $16-\mathrm{km}$ horizontal resolution. A total of 11 horizontal planes with vertical resolution of $0.1 \times$ HPBL made up each trajectory matrix. To filter erroneous trajectories due to truncation and integration error (Stohl 1998; Draxler et al. 2016), forward trajectories were run from the end point of every backward trajectory over the same temporal length, with the resulting trajectory disparity serving as an estimate of the numerical error. Using the backward and forward trajectories, absolute integration error was calculated as half the distance between the start point of the backward trajectory and the end point of the forward trajectory (Draxler et al. 2016; Warner 2018). Trajectories with absolute integration error $>2 \sigma(\approx 370 \mathrm{~km})$ above the sample mean were omitted.

Differentiation between tornadic and nontornadic environments remains an active area of research (e.g., 

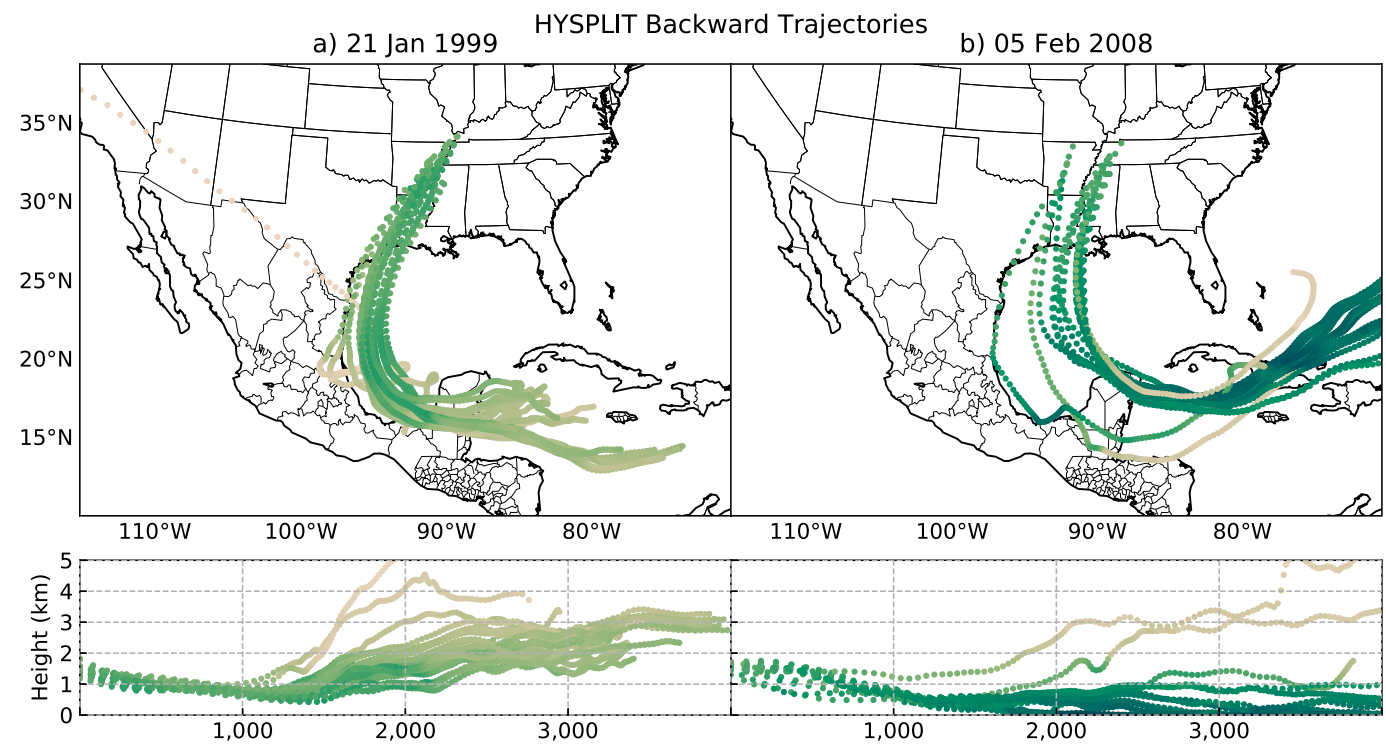

c) 27 Apr 2011

d) 05 May 2007
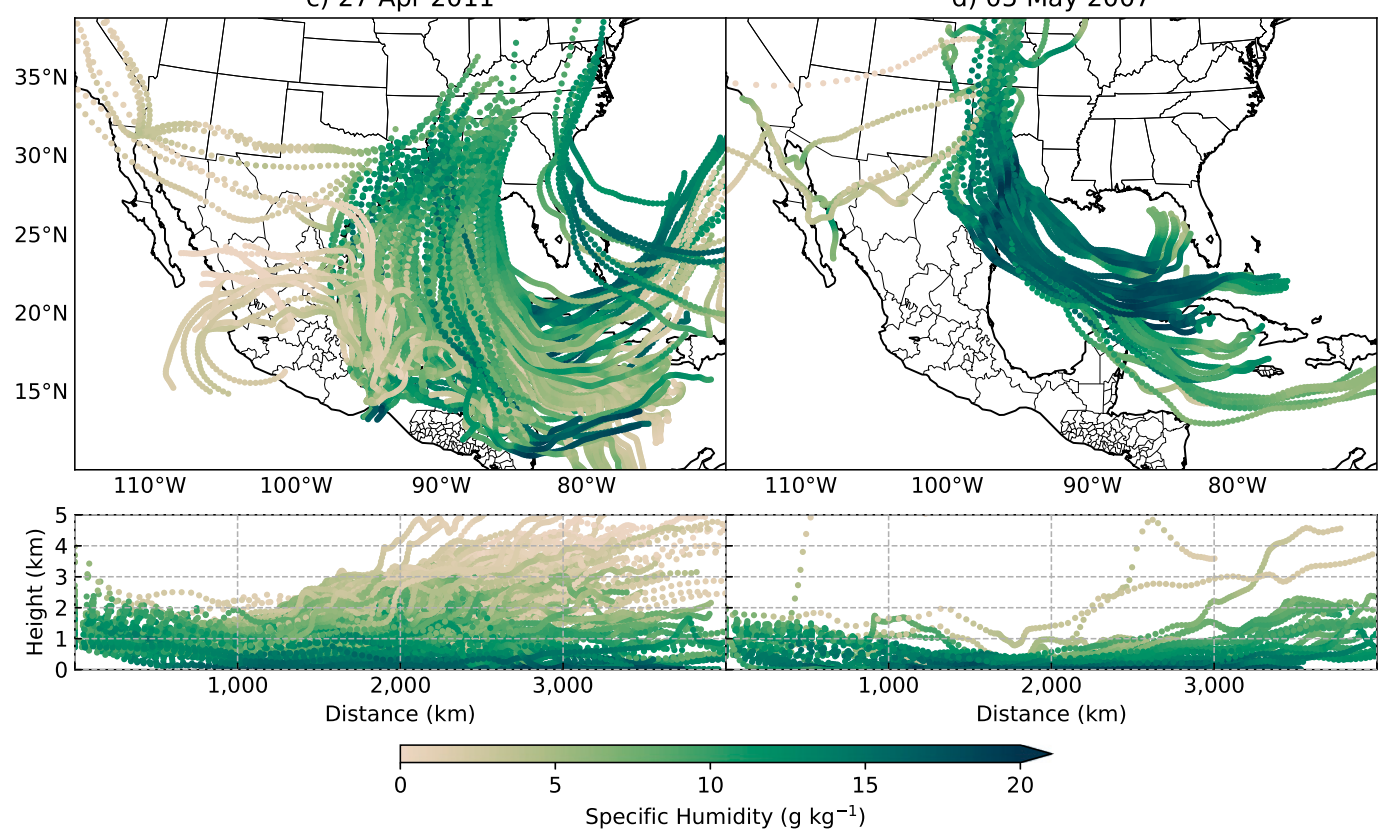

FIG. 1. Backward trajectories with specific humidity $\left(\mathrm{g} \mathrm{kg}^{-1}\right)$ output for select tornado events as illustration of HYSPLIT runs. Vertical cross sections of trajectory path distance $(\mathrm{km})$ and height $(\mathrm{km})$ above ground level (AGL) also included.

Klees et al. 2016; Coffer and Parker 2017). Low-level moisture associated with significant tornado-producing supercells is generally found to be of greater magnitude than low-level moisture of nontornadic supercells (Thompson et al. 2003; Sherburn et al. 2016). It was therefore of interest to investigate whether water vapor sources could serve to discretize between classes of convective events, in this case between significant severe [defined here as EF2+ tornado, hail $>2$ in. $(5.1 \mathrm{~cm})$, and wind $\left.>75 \mathrm{mph}\left(120.7 \mathrm{~km} \mathrm{~h}^{-1}\right)\right]$ and nonsignificant severe. However, this introduces a challenge in categorizing convective events, given that a storm that produces significant severe weather can also produce severe weather below significant criteria. The group "nullsignificant severe" was created to identify nonsignificant severe events, and contains SPC severe reports of hail $\leq 2$ in. $(5.1 \mathrm{~cm})$ and wind $\leq 75 \mathrm{mph}\left(120.7 \mathrm{~km} \mathrm{~h}^{-1}\right)$. These reports were only considered if they occurred during a 24-h period (beginning at 0600 UTC) that had fewer than 6 tornadoes $(\mathrm{EF} 0+)$ and no significant 
tornadoes $(\mathrm{EF} 2+)$. Backward-trajectory matrices for null-significant severe hail and wind reports were generated analogous to tornado trajectory matrices. However, given the much larger frequency of hail and wind reports as compared to tornadoes, the total trajectory count in an individual matrix was reduced to 99 for computational feasibility. The resolution specification of each null-significant severe trajectory matrix is as follows: 9 trajectories per horizontal plane spaced at 32-km horizontal resolution, and 11 horizontal planes centered at the HPBL with vertical resolution of $0.1 \times$ HPBL.

Further discretization between convective classes followed, with the aim to discriminate between water vapor sources of moist environments corresponding to severe thunderstorms and nonsevere events. The nonsevere group was termed "null-severe events" and defined as a 24-h period beginning at 0600 UTC with no reports of $\mathrm{EF} 0+$ tornadoes or hail $\geq 1 \mathrm{in}$. in the $\mathrm{SPC}$ severe event archive. Null-severe event backward trajectories were initiated from geographical areas where the SPC tornado probability climatology ${ }^{2}$ was $\geq 0.1 \%$ for that calendar day, as areas $<0.1 \%$ have a very low climatological probability of a tornado occurrence and thus are unlikely to experience an event (e.g., Fig. 2). The daily SPC tornado probability climatology was created by placing all tornado reports onto an $80-\mathrm{km}$ horizontal resolution grid using dichotomous assignment (e.g., " 0 " for no tornado occurrence and " 1 " for a tornado occurrence), followed by the application of a 15-day temporal Gaussian filter and a $1.5 \sigma$ spatial Gaussian filter (as described by Brooks et al. 2003; Marsh and Brooks 2012). Null-severe event backward trajectories were initialized at each climatology grid point at 1800 UTC, with 11 vertical layers centered at the HPBL with vertical resolution of $0.1 \times$ HPBL.

Along-trajectory meteorological variables and computations were output every hour, including $q\left(\mathrm{~g} \mathrm{~kg}^{-1}\right)$, $\mathbf{V}\left(\mathrm{m} \mathrm{s}^{-1}\right)$, and horizontal moisture flux $\left(\mathrm{m} \mathrm{s}^{-1} \mathrm{~g} \mathrm{~kg}^{-1}\right)$. Horizontal moisture flux was approximated as the product of $\mathbf{V}$ and $q$ (Banacos and Schultz 2005). A Python-based package for HYSPLIT (PySPLIT; Warner 2018) was employed to aid in meteorological variable computations and the bulk generation of backward-trajectory matrices from tornado reports, null-significant severe reports, and null-severe events. To visualize and generate statistical information from trajectories, along-trajectory data were binned onto a 2D grid of daily temporal resolution and $80-\mathrm{km}$ grid spacing-similar to the SPC tornado climatology

\footnotetext{
${ }^{2}$ SPC tornado climatology can be viewed at https://www.spc.noaa.gov/ new/SVRclimo/climo.php?parm=allTorn.
}

(Brooks et al. 2003; Marsh and Brooks 2012)—with each grid cell weighted by daily trajectory frequency. HYSPLIT trajectory visualization was conducted using Matplotlib (Hunter 2007).

\section{b. Identifying moisture sources}

The moisture uptake (MU; $\mathrm{g} \mathrm{kg}^{-1}$ fractional contribution) diagnostic is based on mass conservation principles, in which moisture sources and sinks of an air parcel are assumed to be from evaporation $E$ and precipitation $P$, as detailed in Banacos and Schultz (2005) and Sodemann et al. (2008). The calculation involved a series of steps, which began at the end of each backward trajectory and proceeded forward in time. First, $\Delta q$ was computed every $6 \mathrm{~h}$, a time interval of sufficient length to allow $E$ or $P$ to become the dominant process (Sodemann et al. 2008),

$$
\frac{d q}{d t} \approx \frac{\Delta q}{\Delta t}=E-P\left[\mathrm{~g} \mathrm{~kg}^{-1}(6 \mathrm{~h})^{-1}\right]
$$

As in prior research (e.g., Sodemann et al. 2008; Baldini et al. 2010), an evaporative threshold of $\Delta q \geq 0.2 \mathrm{~g} \mathrm{~kg}^{-1}$ was set in the MU calculation, as $\Delta q<0.2 \mathrm{~g} \mathrm{~kg}^{-1}$ would be insignificant from a thermodynamic perspective. The HPBL was also set as a vertical threshold to discriminate surficial MU from $+\Delta q$ that could be due to physical processes above the HPBL (e.g., convection and evaporating hydrometeors, as discussed in Sodemann et al. 2008). A MU was identified if both conditions were met in a 6 -h period. MU was recorded as a fractional contribution $f$, defined as the quotient of $\Delta q$ and $q$ along the 6-h interval, under the assumption that $\Delta q$ was the net result of $E$ and $P$ (Stohl and James 2004; Pfahl et al. 2014).

As the calculation proceeded forward in time along each trajectory, a weight was assigned to each MU value according to its contribution to $q$ at the meteorological event of interest (Pfahl and Wernli 2008). As in Sodemann et al. (2008) and Pfahl et al. (2014), weights were computed using the quotient of $\Delta q_{m}$ and $q_{n}$, where current 6-h intervals were denoted using the subscript $n$, and past intervals were denoted using the subscript $m$. Along trajectory moisture losses were also accounted for when $\Delta q$ was $\leq-0.2 \mathrm{~g} \mathrm{~kg}^{-1}$ during a 6-h interval, by reducing the weight applied to earlier MU using

$$
\Delta q_{m}^{\prime}=\Delta q_{m}+\left(\Delta q_{n} \times f_{m}\right),
$$

where $\Delta q^{\prime}{ }_{m}$ replaced the previous $\Delta q_{m}$ (Sodemann et al. 2008; Pfahl and Wernli 2008). Given that the goal of the MU computation was to identify the sources of moisture, only backward trajectories from tornado report locations in a sufficiently moist environment were considered. Trajectories were limited to those initialized from grid 


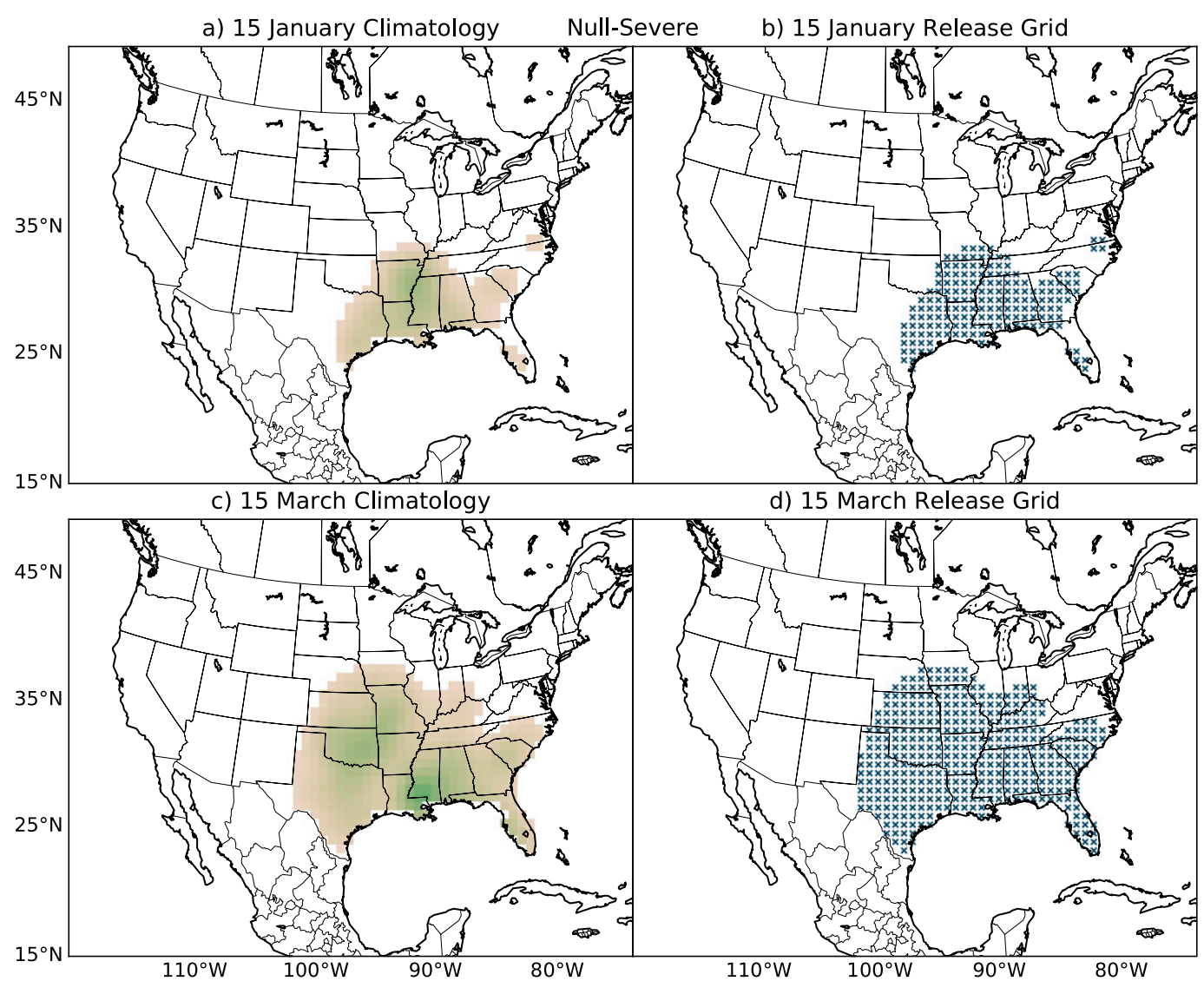

e) 15 May Climatology

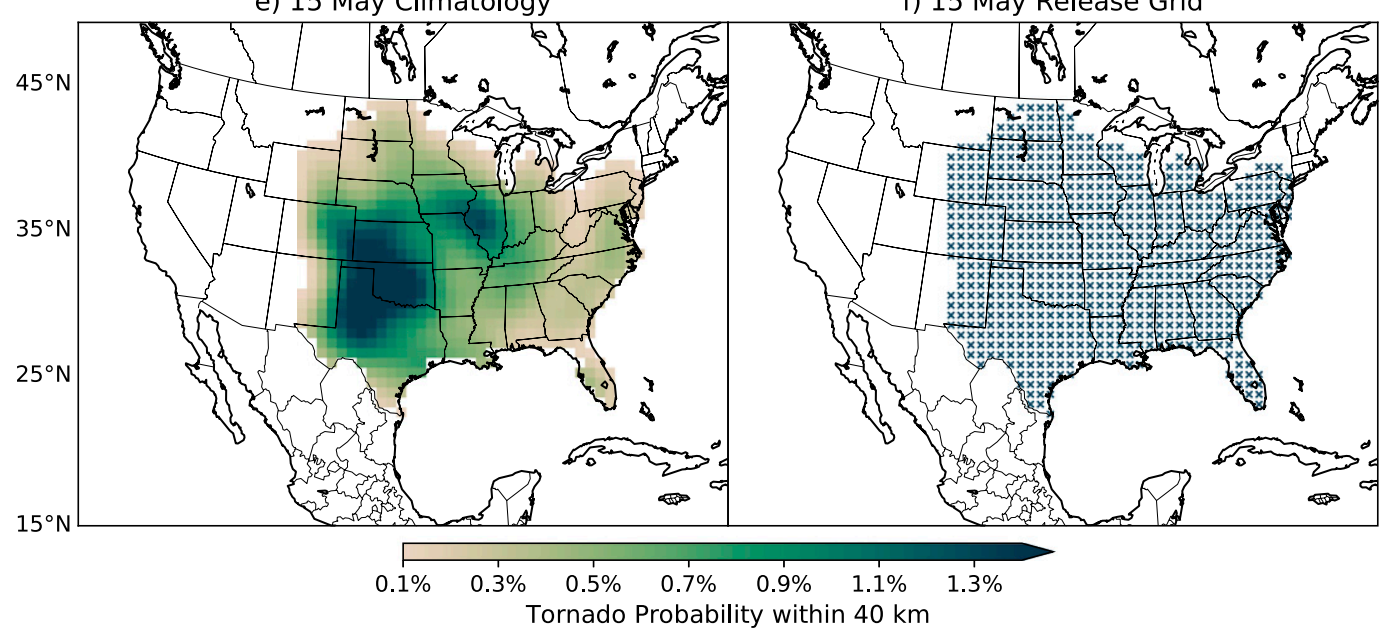

FIG. 2. (left) The daily climatological probability of a tornado within $40 \mathrm{~km}$ and (right) the trajectory initiation locations of null-severe events for (a),(b) 15 Jan, (c),(d) 15 Mar, and (e),(f) 15 May, as examples.

cells with relative humidity $\geq 75 \%$, which was the minimum threshold for relative humidity empirically set in the cloud parameterization scheme of the ETA model for condensation and presence of clouds in a grid cell (Zhao and Carr 1997).

After computations were completed, MU was stratified by source region, including various ocean and marginal sea basins across the study domain. Marine region boundaries were obtained from the International Hydrographic Organization (IHO), and include the GoM, CARIB, NATL, Gulf of California (GoC), and eastern Pacific Ocean (EPAC; Fig. 3). This additional step allowed for quantification of moisture contributions from specific geographical areas. 


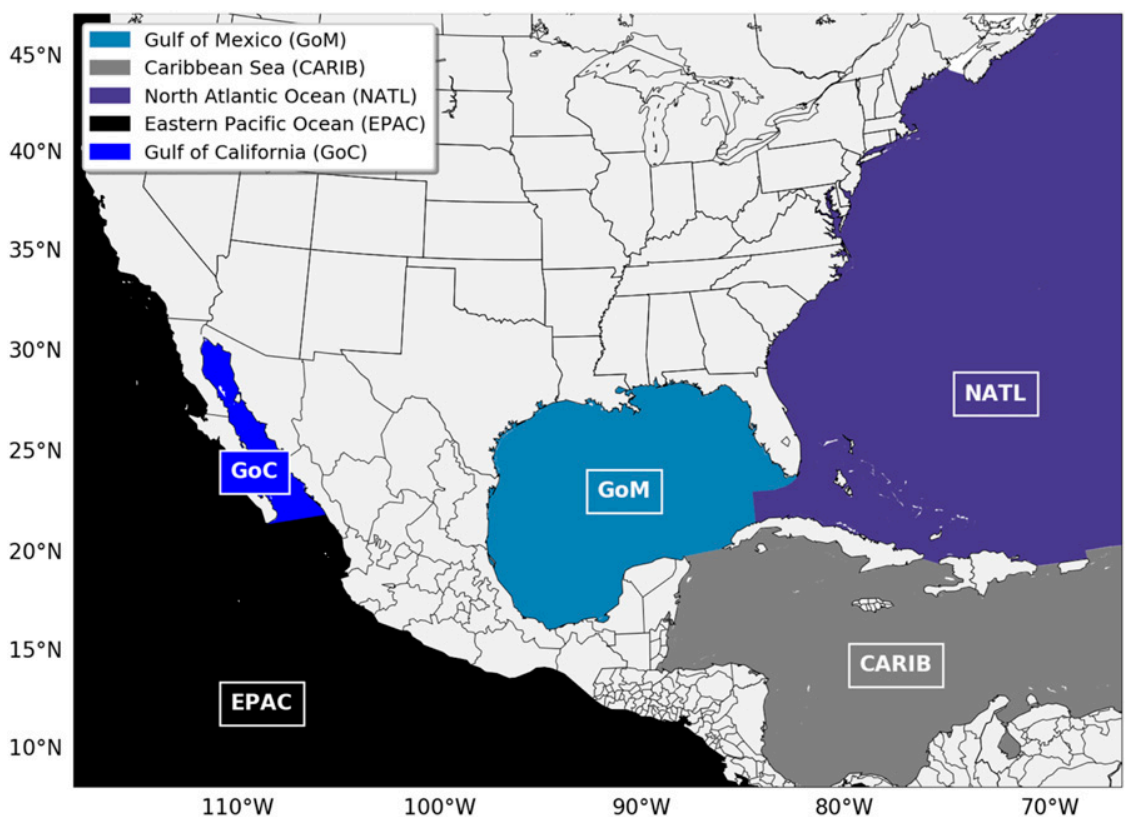

FIG. 3. The Gulf of Mexico (GoM), Caribbean Sea (CARIB), North Atlantic Ocean (NATL), eastern Pacific Ocean (EPAC), and Gulf of California (GoC) marine regions as delineated by the International Hydrographic Organization.

\section{c. Environments}

Oceanic and atmospheric variables were derived to explore their relationships with moisture sources and advection. SSTs underlying trajectories were chosen for analysis because of the positive relationship between SST magnitude and the water content of overlying air masses, as demonstrated by Stephens (1990) and Stephens et al. (1993) using an approximation to the ClausiusClapeyron equation. It was important that SSTs be of sufficient temporal and spatial resolution to detect potential contributions to moisture fluxes along air parcel trajectories. A number of SST datasets span a record of more than 60 years (e.g., extended reconstruction SSTs; Huang et al. 2017), but these records are temporally and spatially coarse (e.g., $2^{\circ}$ and one month), with resolutions that would be insufficient to identify a relationship with MU. The NOAA National Centers for Environmental Information (NCEI) optimum interpolation (OISST) and Advanced Very High Resolution Radiometer (AVHRR) infrared satellite dataset ${ }^{3}$ (1981-2017; Reynolds et al. 2007) provides adequate resolution (e.g., $0.25^{\circ}$ and daily) and was therefore used in this study.

To explore the influence of SSTs on the water vapor content of air parcels $(q)$, SSTs were extracted from

\footnotetext{
${ }^{3}$ OISST was downloaded from http://iridl.ldeo.columbia.edu/ SOURCES/.NOAA/.NCDC/.OISST/.version2/.AVHRR/.sst/.
}

locations where air parcels experienced MU over marine regions using linear interpolation in time and space. SST and $q$ data passed tests of normality, thus a bivariate Pearson correlation $r$ was appropriate to quantify their relationship. Quantification was only conducted for near-surface air parcels, which we surmised were more readily influenced by SSTs. Near-surface air parcels were delimited at $\leq 125 \mathrm{~m}$ for consistency with results from vertical cross-section analyses of the various trajectory climatology groups. Data were binned onto an 80-km grid of daily temporal resolution, analogously to trajectory groups. Statistical significance was determined at each grid point using a two-tailed test $p$ value $(\alpha=0.05)$. Similar to the SPC tornado probability climatology (e.g., Brooks et al. 2003; Marsh and Brooks 2012), a $1.5 \sigma$ spatial Gaussian filter was applied to the binned correlation coefficients to smooth spatial variance.

The advection of moisture often precedes convection formation. The GPLLJ provides an advective mechanism for moisture contributing to severe convective storms of the CONUS and was therefore of interest leading up to tornado events (Helfand and Schubert 1995; Muñoz and Enfield 2011; Weaver et al. 2012). The GPLLJ is generally defined as a meridional wind maximum in the lowest kilometer of the troposphere, climatologically developing in late MAM across the Great Plains and persisting as a nocturnal feature during the summer months (Higgins et al. 1997; Weaver and Nigam 
2008; Krishnamurthy et al. 2015). Wind field convergence at the northern terminus of the GPLLJ can also serve as lift for convective initiation (Gebauer et al. 2018). Here, we approximated the GPLLJ using NARR 925-hPa maximum meridional wind ${ }^{4}$ within the geographical bounds of $25^{\circ}-35^{\circ} \mathrm{N}$ and $102^{\circ}-97^{\circ} \mathrm{W}$, analogous to prior studies (e.g., Muñoz and Enfield 2011; Liang et al. 2015). Grid points where $925 \mathrm{hPa}$ is below ground were discarded.

Similar to the GPLLJ, ETCs can also provide a driver of moisture advection preceding convection (Hawcroft et al. 2012; De Leeuw et al. 2017). ETC tracks were obtained from the Institute for Atmosphere and Climate Science at ETH Zürich (Sprenger et al. 2017), which used European Centre for Medium-Range Weather Forecasts (ECMWF) interim reanalysis (ERA-Interim; Dee et al. 2011) and the Wernli and Schwierz (2006) cyclone tracking algorithm. Wernli and Schwierz (2006) approximate ETC genesis and lysis using a Laplacian operation to identify minimum sea level pressures (SLPs), subsequently demarcating an ETC field using the outermost enclosed SLP contour. An inherent limitation in tracking atmospheric features is that no algorithm will capture the full range of possible events (Walters and Winkler 2001; Hodges et al. 2011), which will lead to the inadvertent omission of certain occurrences. However, Raible et al. (2008) and Neu et al. (2013) found the Wernli and Schwierz (2006) algorithm to perform with skill and comparably to others (e.g., Murray and Simmonds 1991; Blender et al. 1997), with differences primarily occurring when tracking ETCs of weak intensity.

We hypothesized that more intense ETCs could lead to greater moisture transport, priming a favorable environment for convection. To quantify the potential relationship, the minimum pressure of ETCs associated with meteorological events of interest were extracted for analysis. ETCs with distances from tornado events greater than $1000 \mathrm{~km}$ were omitted from analysis, given that ETC influence on the environments of convective events wanes with distance (Doswell and Bosart 2001; Metz et al. 2004). A bivariate Pearson correlation was performed between ETC minimum pressure and mean horizontal moisture flux (MF; $\mathrm{g} \mathrm{kg}^{-1}$ ) that occurred within $24 \mathrm{~h}$ of the event, as earlier MF could have been influenced by other features (e.g., Intra-Americas Sea low-level jet; Muñoz and Enfield 2011). Statistical significance was determined using a two-tailed test $p$ value $(\alpha=0.05)$. This analysis was also conducted for the

\footnotetext{
${ }^{4}$ NARR data can be obtained from https://www.esrl.noaa.gov/ $\mathrm{psd} /$ data/gridded/data.narr.html.
}

GPLLJ magnitude and MF that occurred within $24 \mathrm{~h}$ of the event of interest for the month of May.

\section{Results}

\section{a. Moisture origins: Tornadic events}

\section{1) EF1+ AND SIGNIFICANT TORNADOES}

The mean atmospheric state differs considerably during DJF and MAM across the CONUS and shapes the climatological frequency and geographical extent of tornadoes (Brooks et al. 2007). The origins and advection paths of air masses contributing to EF1+ and significant tornadoes also exhibit a seasonal cycle, with many large-scale dynamic and kinematic (e.g., ETCs, GPLLJ) factors driving airmass advection (e.g., Doswell et al. 1996). Backward air parcel trajectories initiated from EF1+ tornado events show peak monthly mean frequency across the GoM and northwestern CARIB (Fig. 4). The overall directional wind field across the GoM has a southerly meridional component (Fig. 4), which could be partly related to the influence of ETCs. Before air parcels reach the GoM basin, they generally travel across the western NATL or CARIB with an easterly velocity component, likely influenced by trade winds or the Caribbean component of the IntraAmericas Sea low-level jet (Muñoz and Enfield 2011). While small in frequency $(<2 \%)$, some air parcels preceding EF1 + tornadic events do originate from the GoC and EPAC (Fig. 4). These trajectories may be associated with convection west of the Continental Divide, as explained by Hagemeyer (1991), or could be erroneous because of limitations of NARR in deciphering meteorological advection over the complex topography of the Rocky Mountains (e.g., Sheffield et al. 2012).

The GoM is the primary contributor of moisture to EF1 + tornadic convection during both DJF and MAM (Fig. 5). When analyzing moisture contributions of the GoM on a monthly basis, it becomes evident that there is intraseasonal variability. During DJF, $58 \%$ of moisture originates from the GoM in December, which decreases to $51 \%$ in January and February (Figs. $5 \mathrm{a}-\mathrm{c}$ ). This reduction is likely related to the seasonal cycle of GoM SSTs, which undergo cooling from cold air intrusions (Zavala-Hidalgo et al. 2002). The northwestern CARIB and western NATL (Florida Strait) also play meaningful roles in DJF, providing more than $19 \%$ and $12 \%$ of total moisture, respectively (Figs. 5a-c). These results suggest that synoptic-scale forcing can advect moisture from regions far displaced from the CONUS within relatively short time frames, which is physically reasonable (e.g., Eichler and Higgins 2006); DJF tornadic events are 

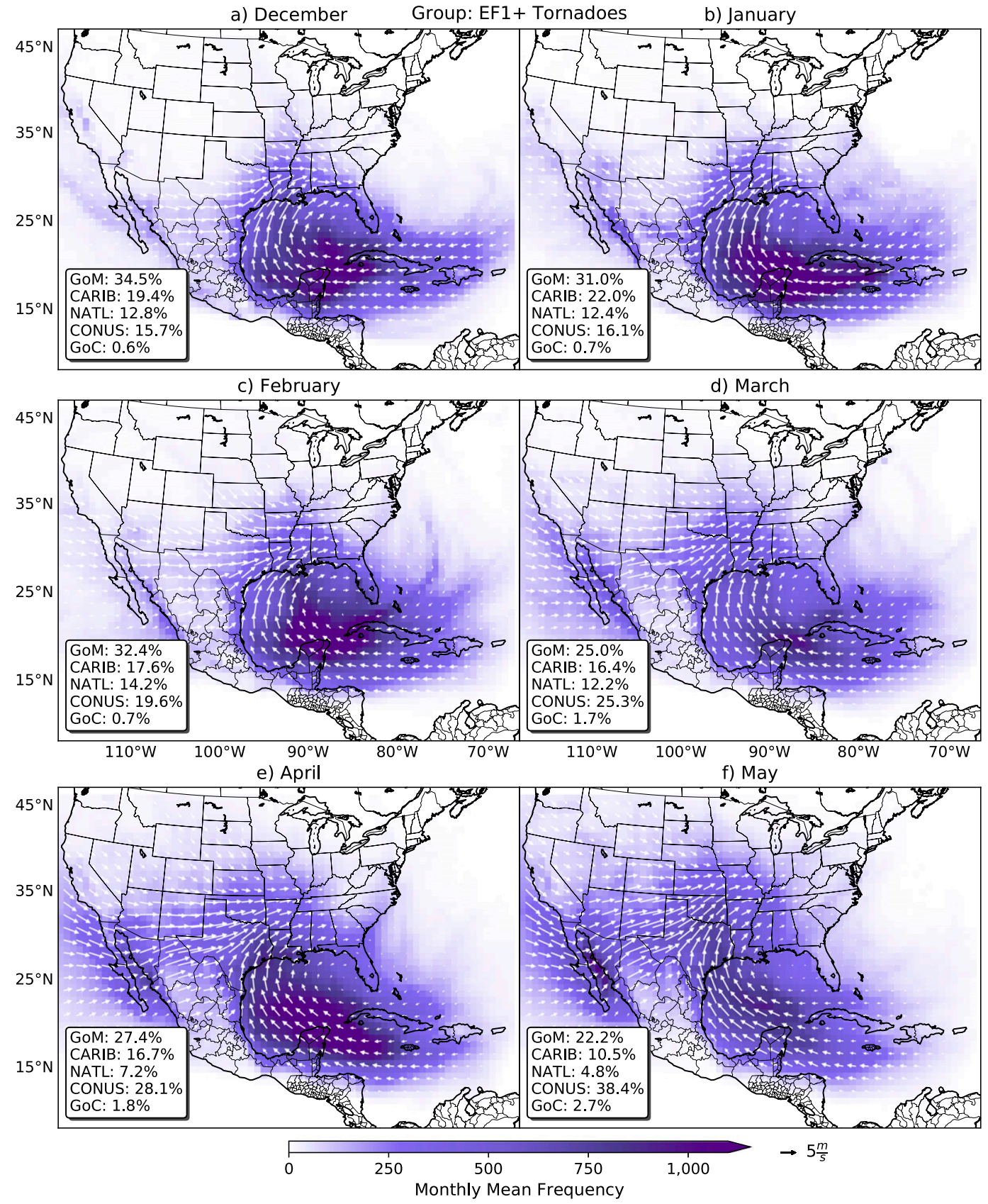

FIG. 4. Monthly mean frequency of backward-trajectory matrices initiated from EF1+ tornadoes (1981-2017) with percentage of frequency per marine region, as delineated in Fig. 3. Velocity vectors show mean forward speed and direction of air parcels at each grid point.

associated with ETCs, which are sources of substantial meridional forcing (Doswell and Bosart 2001; Metz et al. 2004). The large moisture contributions across the southeastern GoM, Yucatán Channel, and Florida Strait overlap with the climatology of the LC (Figs. 5a-c; Vukovich 2007), providing evidence of its importance as a source of moisture for DJF tornadic convection, as Molina et al. (2016) found for MAM.
The moisture sources of EF1+ tornadic convection exhibit spatial and magnitude uniformity throughout DJF, but the months of MAM are dissimilar, characterized by a seasonal evolution toward increasingly local moisture sources. During the month of March, for example, more than $34 \%$ of moisture originates from the CARIB and NATL combined, a percentage that decreases by half in the month of May (Figs. 5d-f). The 

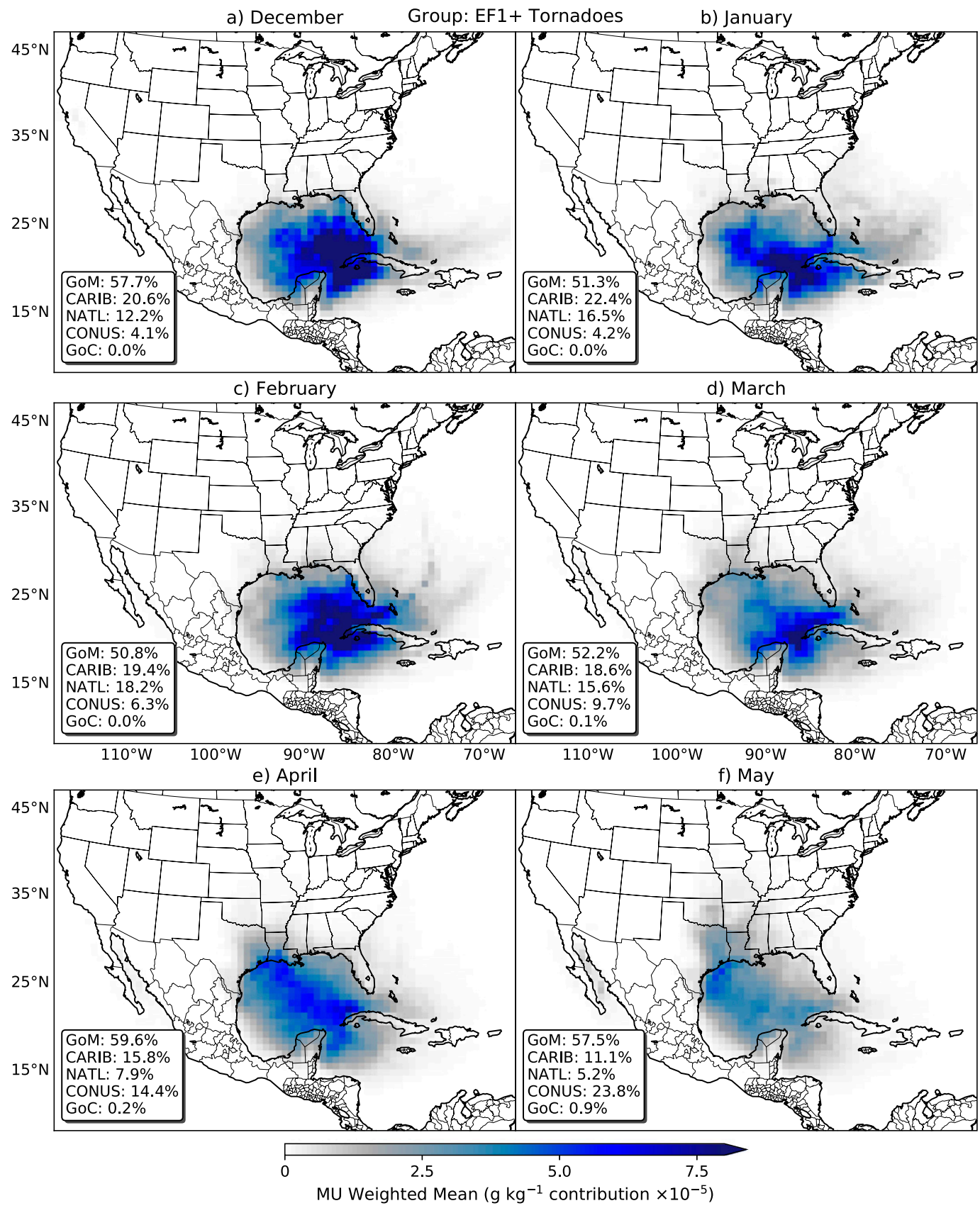

FIG. 5. Monthly MU-weighted fractional contributions of EF1 + tornadoes (1981-2017) with percentage of MU per marine region, as delineated in Fig. 3.

CONUS becomes a greater contributor of moisture in late MAM (Fig. 5f) with water likely evaporating from terrestrial sources via evapotranspiration (Clark and Arritt 1995), partly because of EF1+ tornadic convection being more readily influenced by mesoscale features (e.g., outflow boundaries, drylines). Notably, MU contributions during the month of May resemble the GPLLJ climatological occurrence across eastern Texas and Oklahoma, consistent with the physical mechanisms driving this process (Weaver et al. 2012). Late MAM is also characterized by small moisture contributions from the $\mathrm{GoC}(<1 \%)$, likely related to convection west of the Continental Divide as discussed by Hagemeyer (1991) or NARR low-level moisture errors (e.g., Gensini et al. 2014). We note that moisture source seasonal differences could be partly related to the spatial characteristics of tornado climatology (e.g., Brooks et al. 2003). 


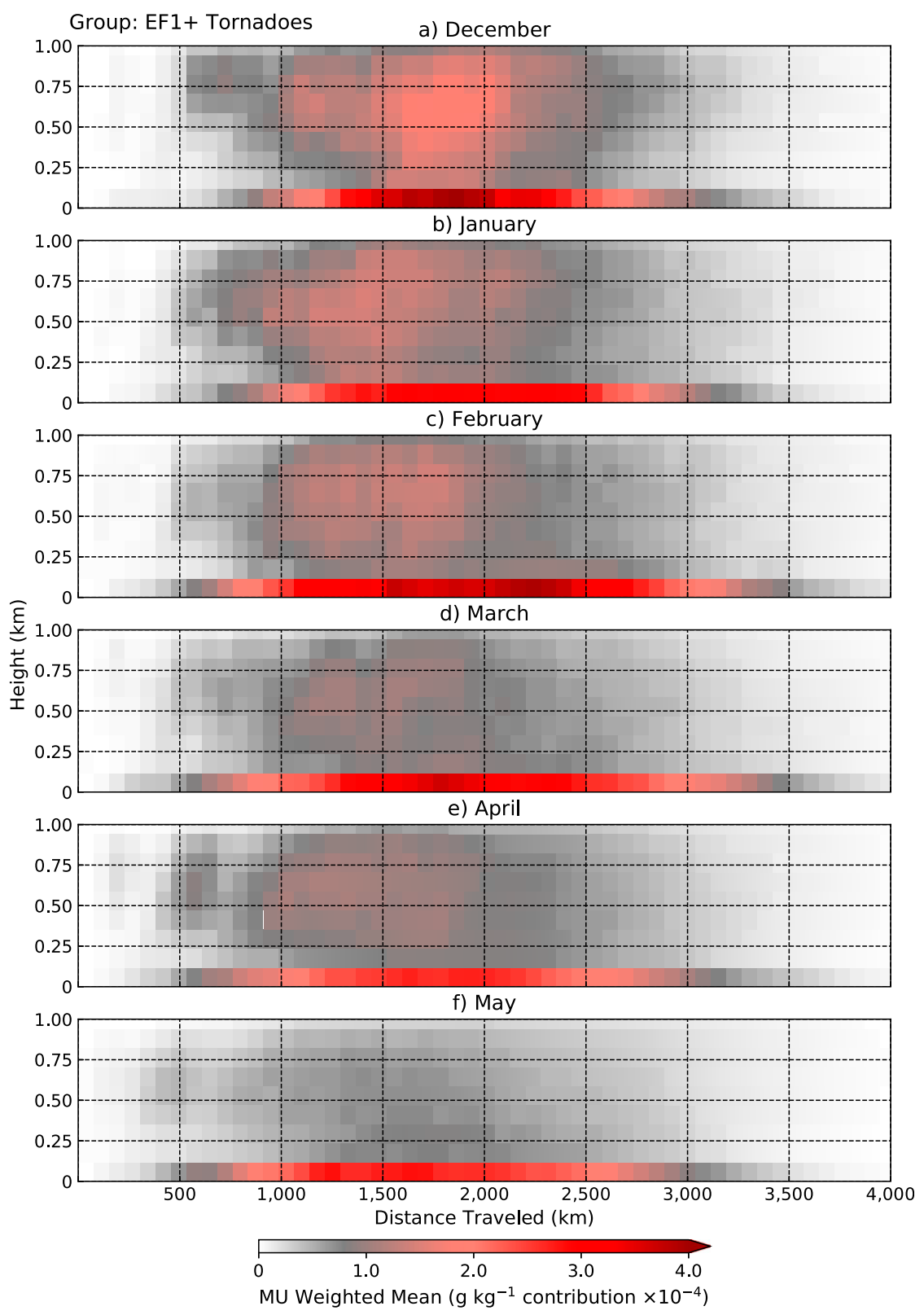

FIG. 6. Vertical cross sections of monthly MU-weighted fractional contributions of EF1+ tornadoes (1981-2017). Heights are AGL.

Vertical cross sections of backward-trajectory matrices show that most moisture for EF1+ tornadic convection originates from surficial sources, within the lowest $125 \mathrm{~m}$ of the troposphere (Fig. 6). Air parcels acquire most moisture at distances of $1000-2500 \mathrm{~km}$ from EF1+ tornadic thunderstorms of the DJF season, emphasizing that moisture does not tend to originate locally for DJF tornadoes (Figs. 6a-c). During MAM, air parcels attain most moisture across a broader distance range of 500-2500 km from EF1+ tornado events (Figs. 6d-f). Warm SSTs likely enhance evaporative fluxes along air parcel trajectories during all months, with increased local moisture availability from continental sources playing a more substantial role later in MAM. It is interesting that some MU occurs above $125 \mathrm{~m}$ (but at or below the HPBL) at the same distances as peak MU values, a signal that is most pronounced in early DJF and decreases in magnitude every month thereafter (Fig. 6). Elevated moisture gains could be related to (i) air parcels interacting with buoyant air masses rising from below because of unstable thermodynamic vertical profiles that are deeper than the 
TABLE 1. Summary of MU results for the GoM basin and CONUS.

\begin{tabular}{|c|c|c|c|c|c|c|}
\hline & Dec & Jan & Feb & Mar & Apr & May \\
\hline \multicolumn{7}{|c|}{ MU summary (from GoM) } \\
\hline EF1+ tornadoes & $58 \%$ & $51 \%$ & $51 \%$ & $52 \%$ & $60 \%$ & $58 \%$ \\
\hline $\mathrm{EF} 2+$ tornadoes & $48 \%$ & $50 \%$ & $46 \%$ & $50 \%$ & $59 \%$ & $60 \%$ \\
\hline $\mathrm{EF} 1+$ tornado outbreaks & $57 \%$ & $49 \%$ & $47 \%$ & $49 \%$ & $58 \%$ & $57 \%$ \\
\hline $\mathrm{EF} 2+$ tornado outbreaks & $37 \%$ & $53 \%$ & $39 \%$ & $49 \%$ & $61 \%$ & $64 \%$ \\
\hline Null-significant severe & $67 \%$ & $64 \%$ & $63 \%$ & $58 \%$ & $55 \%$ & $41 \%$ \\
\hline Null-severe & $46 \%$ & $43 \%$ & $35 \%$ & $27 \%$ & $22 \%$ & $16 \%$ \\
\hline \multicolumn{7}{|c|}{ MU summary (from CONUS) } \\
\hline EF1+ tornadoes & $4 \%$ & $4 \%$ & $6 \%$ & $10 \%$ & $14 \%$ & $24 \%$ \\
\hline $\mathrm{EF} 2+$ tornadoes & $3 \%$ & $4 \%$ & $6 \%$ & $9 \%$ & $13 \%$ & $21 \%$ \\
\hline EF1+ tornado outbreaks & $4 \%$ & $5 \%$ & $6 \%$ & $10 \%$ & $13 \%$ & $22 \%$ \\
\hline $\mathrm{EF} 2+$ tornado outbreaks & $3 \%$ & $4 \%$ & $4 \%$ & $11 \%$ & $11 \%$ & $16 \%$ \\
\hline Null-significant severe & $14 \%$ & $17 \%$ & $16 \%$ & $29 \%$ & $35 \%$ & $53 \%$ \\
\hline Null-severe & $54 \%$ & $58 \%$ & $63 \%$ & $69 \%$ & $67 \%$ & $66 \%$ \\
\hline
\end{tabular}

HPBL, (ii) travel across cloud condensation, (iii) topography-related errors from the Rockies or Caribbean, or (iv) precipitation falling along air parcel trajectories. Reasoning for elevated moisture gains will be explored in greater detail in future work.

Moisture origins of significant tornado events are farther displaced from the CONUS as compared to moisture origins of EF1+ tornadoes during all months considered. For instance, as compared to DJF EF1+ tornado climatology, moisture contributions to significant tornadoes increase from the CARIB and NATL and decrease from the GoM by roughly $\pm 5 \%$ (Table 1 ). These results suggest that greater synoptic-scale forcing preceding stronger tornado events can drive moisture advection from more distant source regions.

\section{2) OUTBREAK TORNADO EVENTS}

Most fatalities associated with tornadoes occur during severe thunderstorm events resulting in a substantial number of tornadoes, referred to as tornado "outbreaks." For example, when defining a tornado outbreak as the occurrence of six or more EF1+ tornadoes during a 24-h period beginning at 0600 UTC, tornado outbreaks account for $67 \%$ of tornado-related fatalities during the DJF and MAM seasons (1953-2017). However, there is no formalized definition derived from a physical basis for a tornado outbreak (Verbout et al. 2006; Doswell et al. 2006). Many previously defined thresholds vary considerably, arbitrarily based on the needs of the research question at hand (e.g., Mercer et al. 2009; Fuhrmann et al. 2014; Tippett et al. 2016; Cook et al. 2017). Nevertheless, the large number of fatalities associated with high tornado frequencies raises our interest in exploring whether moisture sources of tornado outbreaks were distinct from that of all EF1+ and significant tornadoes. In an effort to define a tornado outbreak with some objectivity for this study, empirical cumulative distribution functions (ECDFs) were generated for $\mathrm{EF} 1+$ and significant tornado totals during a 24-h period beginning at 0600 UTC (Fig. 7). ECDFs reveal that most EF1+ tornado outbreaks can be encapsulated using a threshold of six EF1+ tornadoes per day, and most significant tornado outbreaks can be encapsulated using a threshold of five significant tornadoes per day (Fig. 7). These thresholds were used to explore the moisture origins of EF1+ and significant tornado outbreaks.

The moisture origins and advection patterns of EF1+ tornado outbreaks are similar to that of all tornadoes: (i) more than $47 \%$ of moisture originates from the GoM each month, (ii) large contributions overlap the LC region, and (iii) moisture origins become increasingly continental in late MAM (Fig. 8). However, there are also some dissimilarities. Results show that peak MU fractional contributions are approximately double in magnitude for EF1+ tornado outbreaks (Fig. 8) as compared to all EF1+ tornado events, suggesting that tornado outbreaks stem from air masses with greater moisture content than non-tornado-outbreak counterparts. The greater moisture content of air masses associated with $\mathrm{EF} 1+$ tornado outbreaks is also reflected in vertical cross sections of backward-trajectory matrices, which also show that most moisture evaporates from surficial sources at distances of $1000-3000 \mathrm{~km}$ from EF1+ tornado outbreaks (Fig. 9).

Moisture sources of significant tornado outbreaks are similar to those of EF1+ tornado outbreaks, at times originating from regions farther displaced from the CONUS (Table 1). For instance, MU from the CARIB increased by roughly $10 \%$ in December and February, suggesting that moisture contributing to significant tornado outbreaks is transported by stronger meridional forcing than moisture contributing to EF1+ tornado outbreaks. Similarly, significant tornado outbreaks during the month of May were associated with a reduction in moisture from the CONUS and an increase in moisture from the GoM (Table 1), suggesting that land surface moisture is not sufficient alone for significant tornado outbreaks until perhaps later in the summer.

\section{b. Moisture origins: Nontornadic events}

\section{1) Null-SigNifiCANT SEVERE}

In previous sections, the origins and advection patterns of moisture contributing to tornado events were identified, broadening our understanding of the largescale hydrological cycle in relation to tornadic thunderstorms. Here we explore moisture contributions to null-significant severe events and find that their 
a) December

EF1+ and EF2+ Tornadoes

b) January

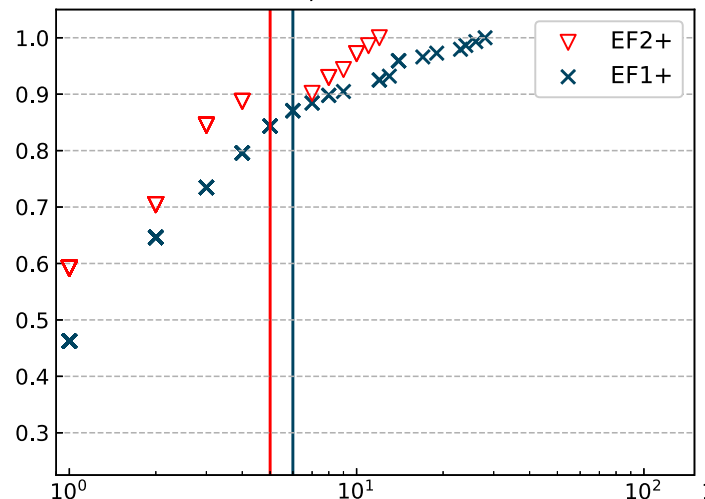

c) February
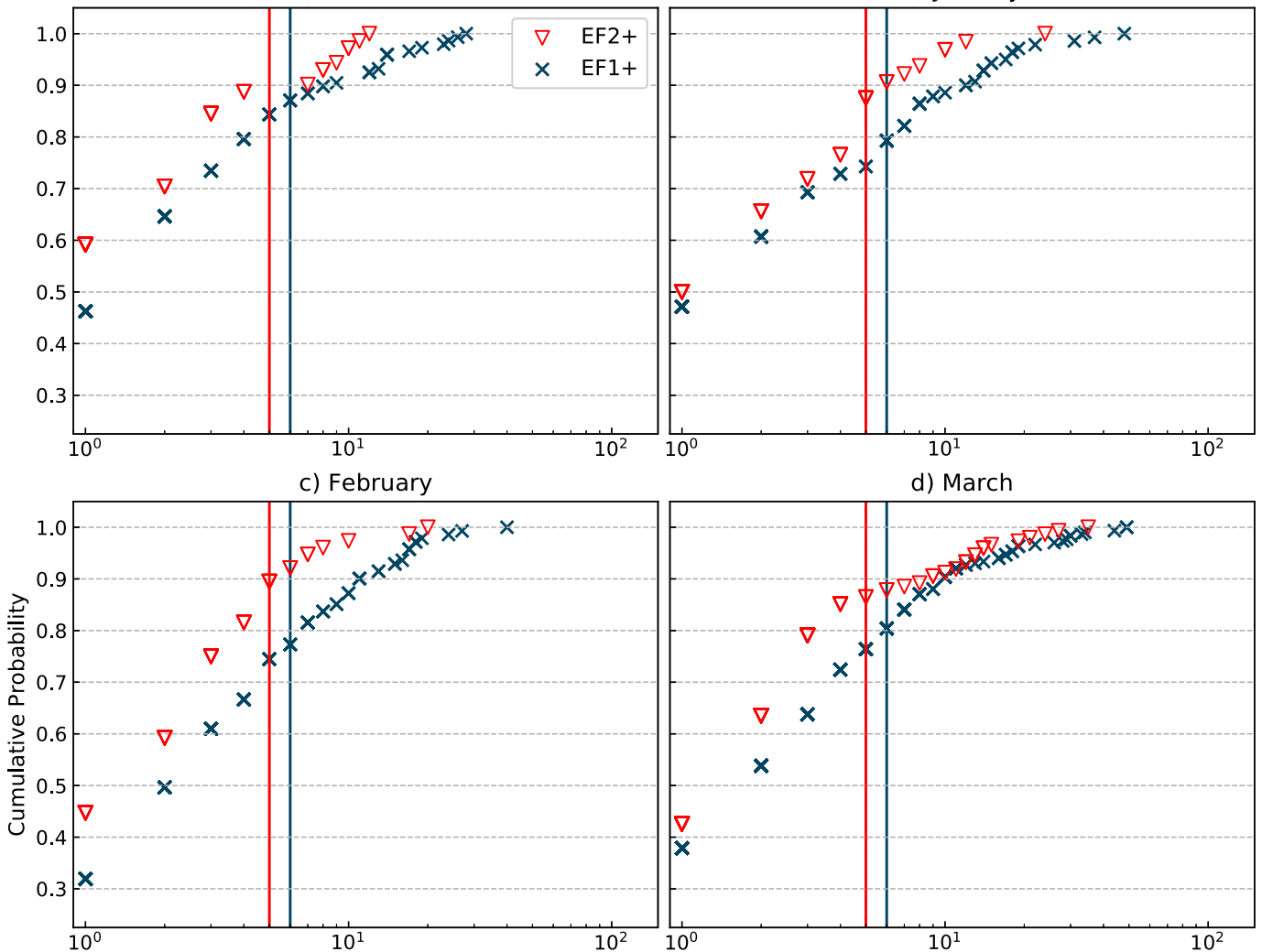

d) March

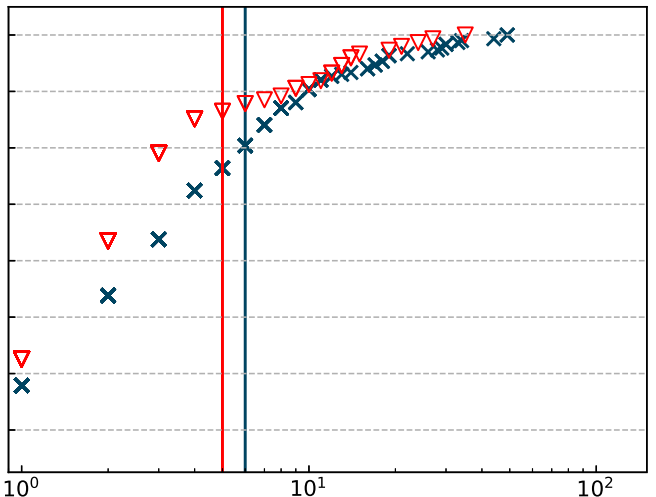

e) April

f) May
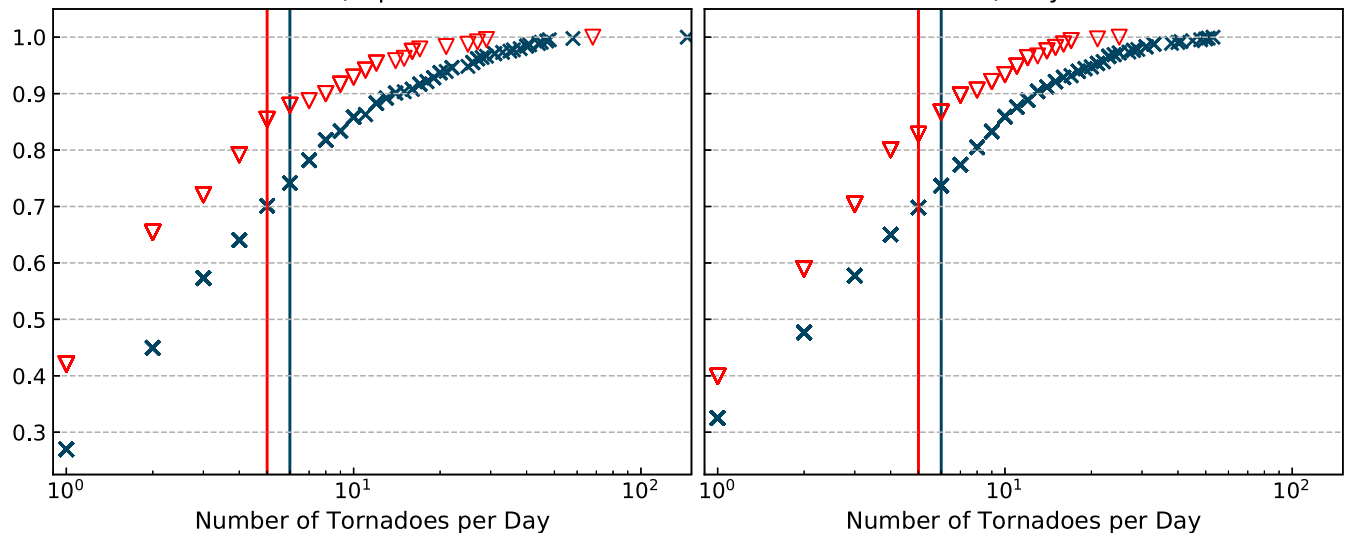

FIG. 7. Empirical cumulative distribution functions of EF1+ and significant (EF2+) tornadoes per 24-h period beginning at 0600 UTC using a logarithmic scale (1981-2017). The vertical lines represent the thresholds for tornado outbreaks (dark blue) and significant tornado outbreaks (red).

moisture sources are more proximal to the CONUS than moisture sources of tornadic events (Fig. 10). In DJF for example, more than $60 \%$ of moisture contributing to null-significant severe events originates from the GoM. Similarly, continental-based contributions exceed $50 \%$ in late MAM (Fig. 10). Late MAM moisture contributions coincide with the GPLLJ climatology (Weaver et al. 2012), akin to the tornadic counterparts. The reduction in advection distances of moisture could be related to weaker large-scale meridional transport. The seasonal cycle also appears to exert an influence on moisture contributions to null-significant severe events, given that MU increases in magnitude from December through May as mean atmospheric temperatures and SSTs rise. The peak magnitudes of MU fractional contributions of null-significant severe events are approximately 0.5 of those of tornadic events and 0.25 of those of EF1+ tornado outbreaks (Fig. 10). 
a) December Group: EF1+ Outbreaks

b) January
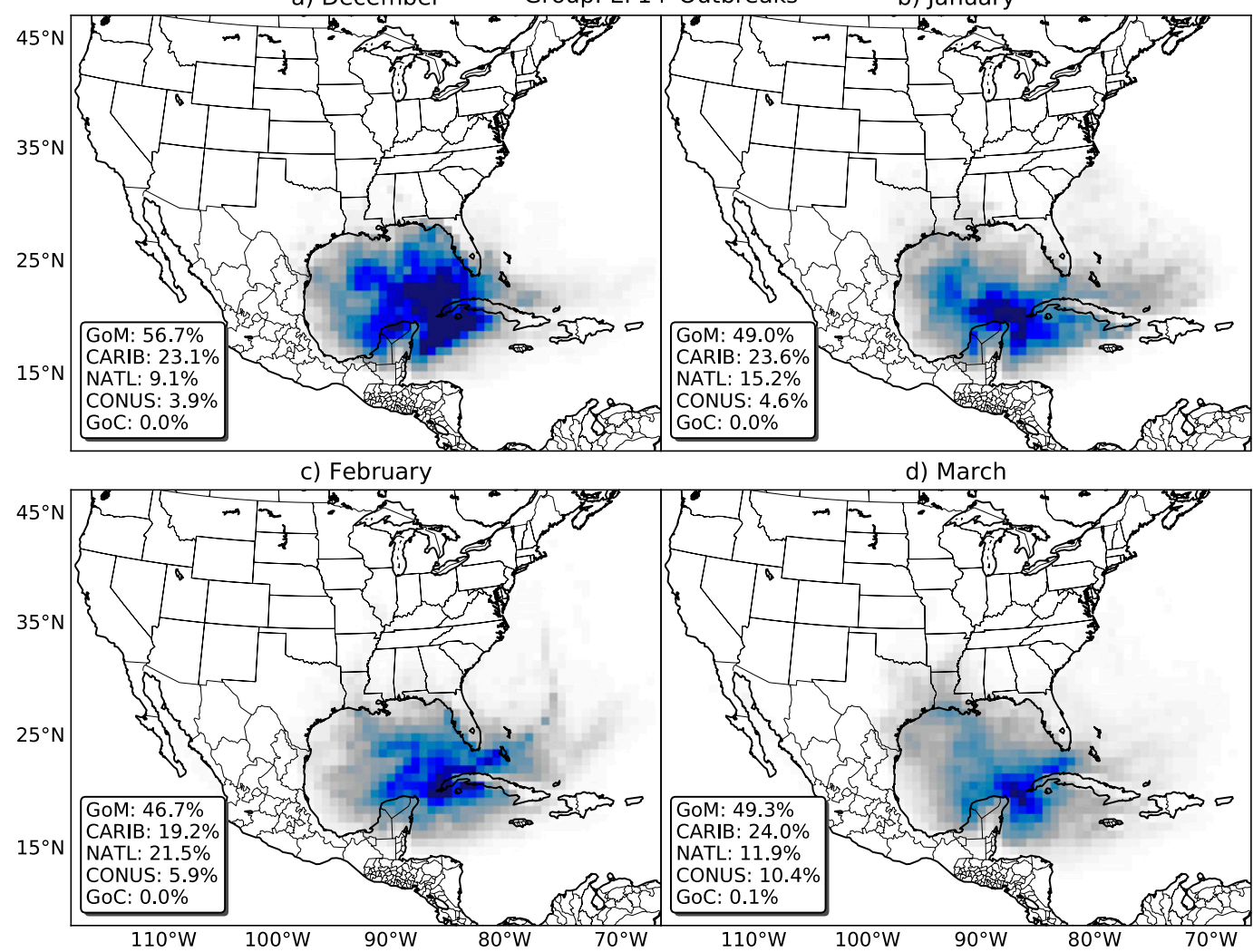

d) March

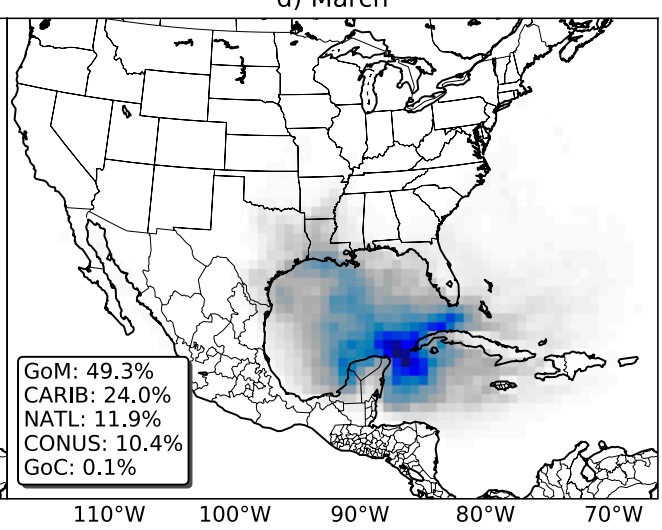

e) April

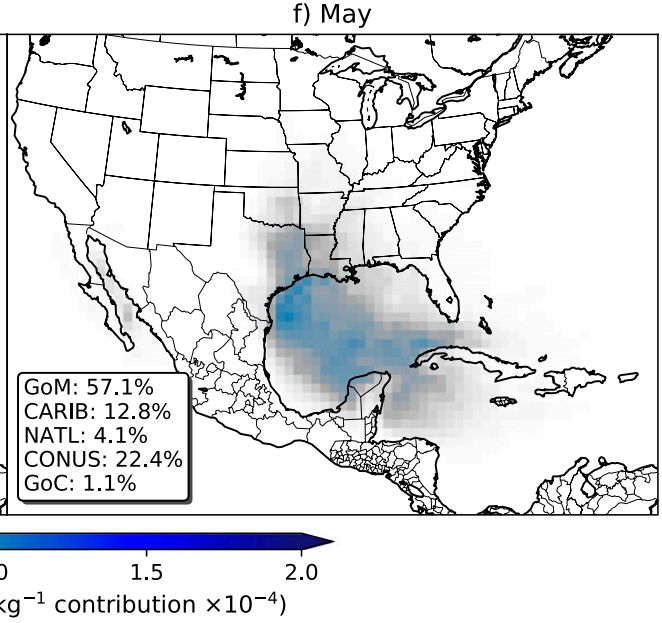

FIG. 8. Monthly MU-weighted fractional contributions of EF1 + tornado outbreaks (1981-2017) with percentage of MU per marine region, as delineated in Fig. 3.

The vertical cross sections of trajectory matrices initiated from null-significant severe events substantiate the aforementioned results. Peak MU occurs at more proximal distances to null-significant severe events as compared to tornadic thunderstorms and tornado outbreaks (Fig. 11). The magnitude of MU also increments on a monthly basis from December through May. Vertical cross sections of trajectory matrices also reveal that the vast majority of moisture originates from surficial sources (height $\leq 125 \mathrm{~m}$; Fig. 11).

\section{2) NuLL-SEVERE EVENTS}

The moisture origins of null-severe events are distinct from those of other backward-trajectory groups considered thus far. Land areas (e.g., soil and vegetation) are the predominant sources of moisture for null-severe 


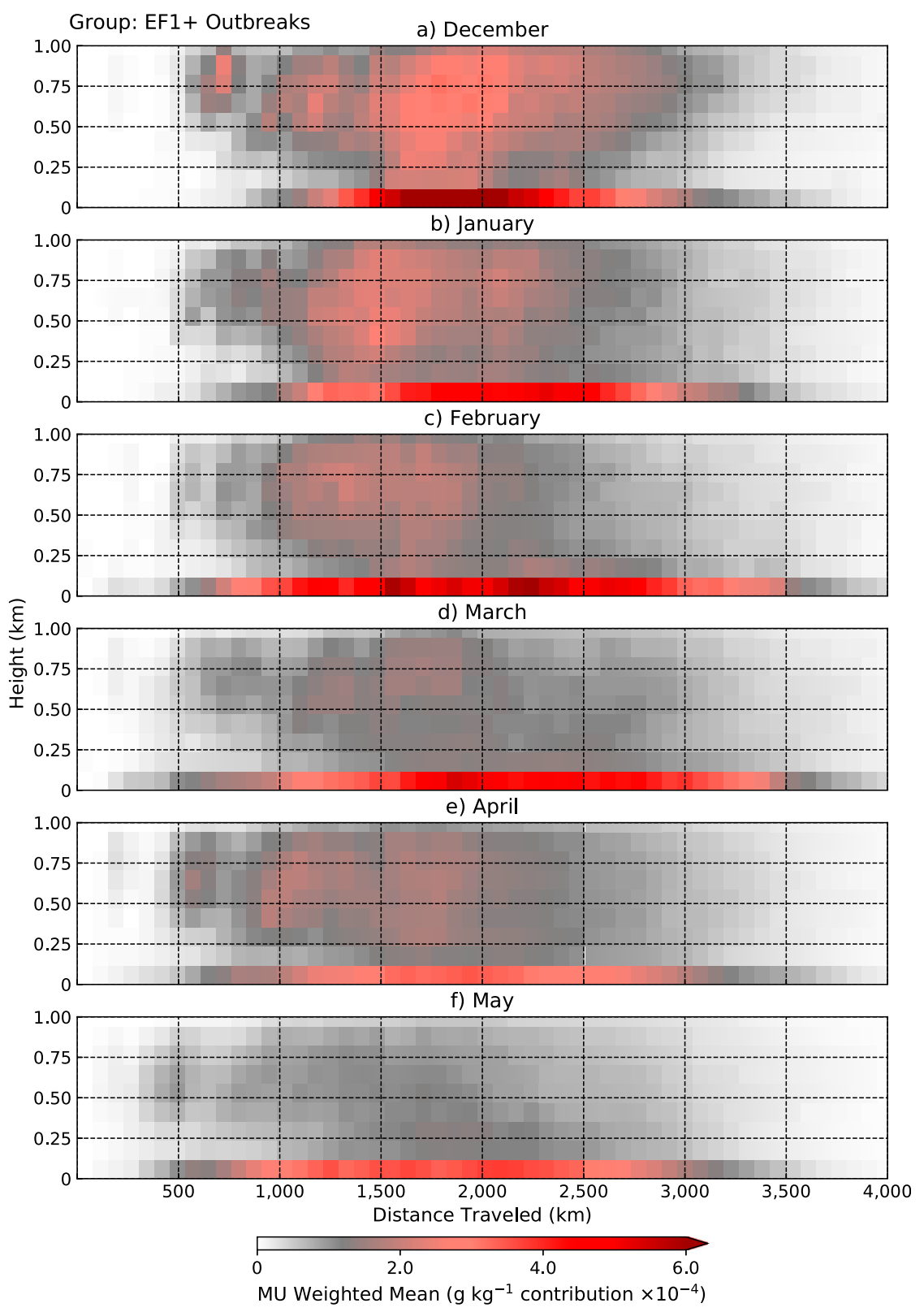

FIG. 9. Vertical cross sections of monthly MU-weighted fractional contributions of EF1+ tornado outbreaks (1981-2017). Heights are AGL.

events, with soil moisture likely preconditioned by prior precipitation events (Bohlinger et al. 2017, 2018). Land areas constitute $54 \%$ of total moisture contributions in December and subsequently increase to $66 \%$ in May (Fig. 12). The northern GoM is also an important contributor in early DJF, but its influence wanes in late MAM (Fig. 12). Almost no moisture originates from the CARIB during any of the months considered, which suggests that moisture advection is weaker preceding null-severe events as compared to tornadic and null- significant severe events. Moisture contributions from the NATL increase in late MAM, possibly in association with the seasonal cycle driving warmer SSTs across areas just off the Eastern Seaboard (e.g., Gulf Stream Current), the Florida Strait, and the Bahamas region (Fig. 12).

Vertical cross sections of backward-trajectory matrices corroborate results and show that moisture origins of null-severe events are more proximal than moisture origins of other trajectory groups analyzed so 


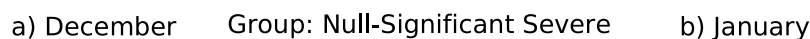
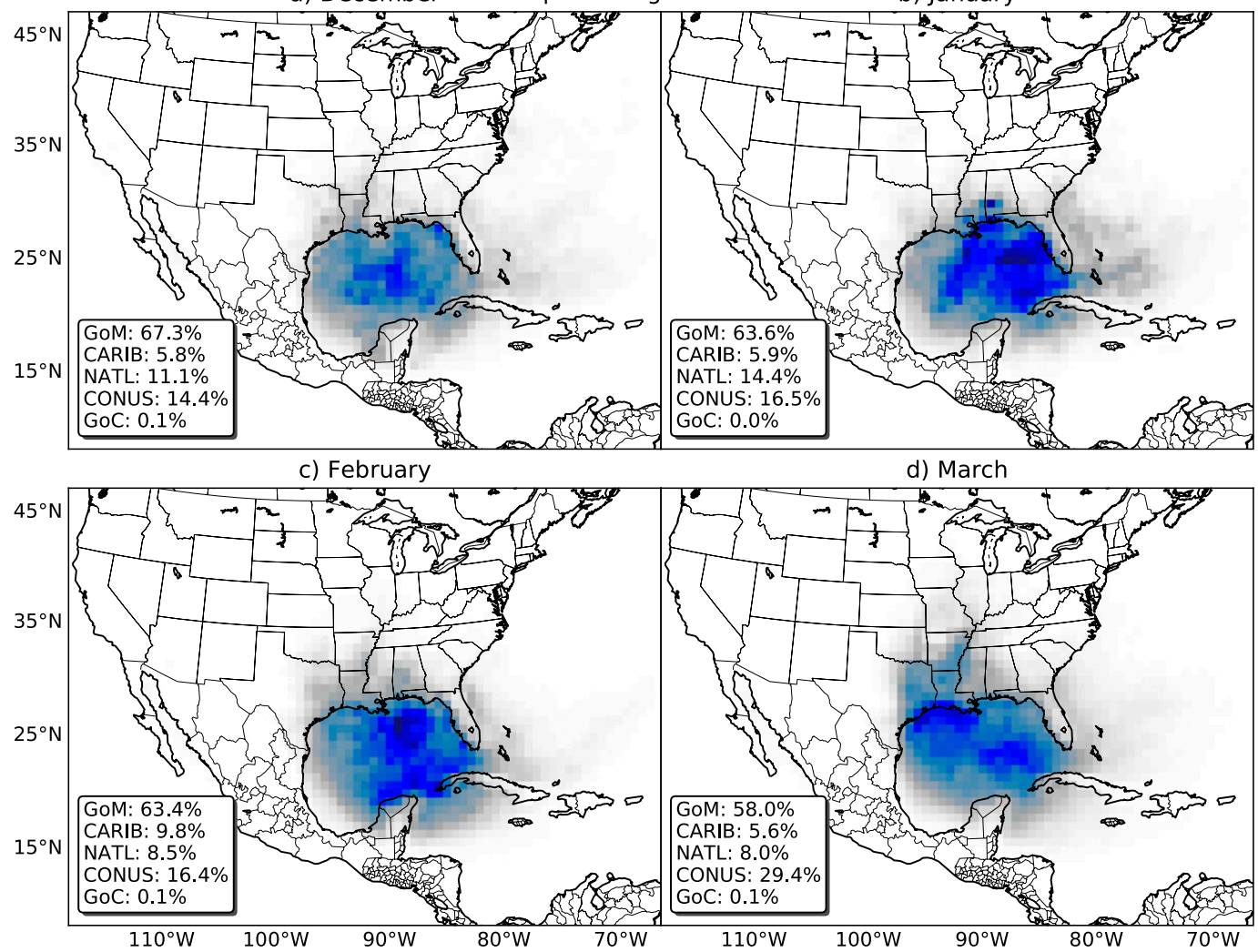

d) March
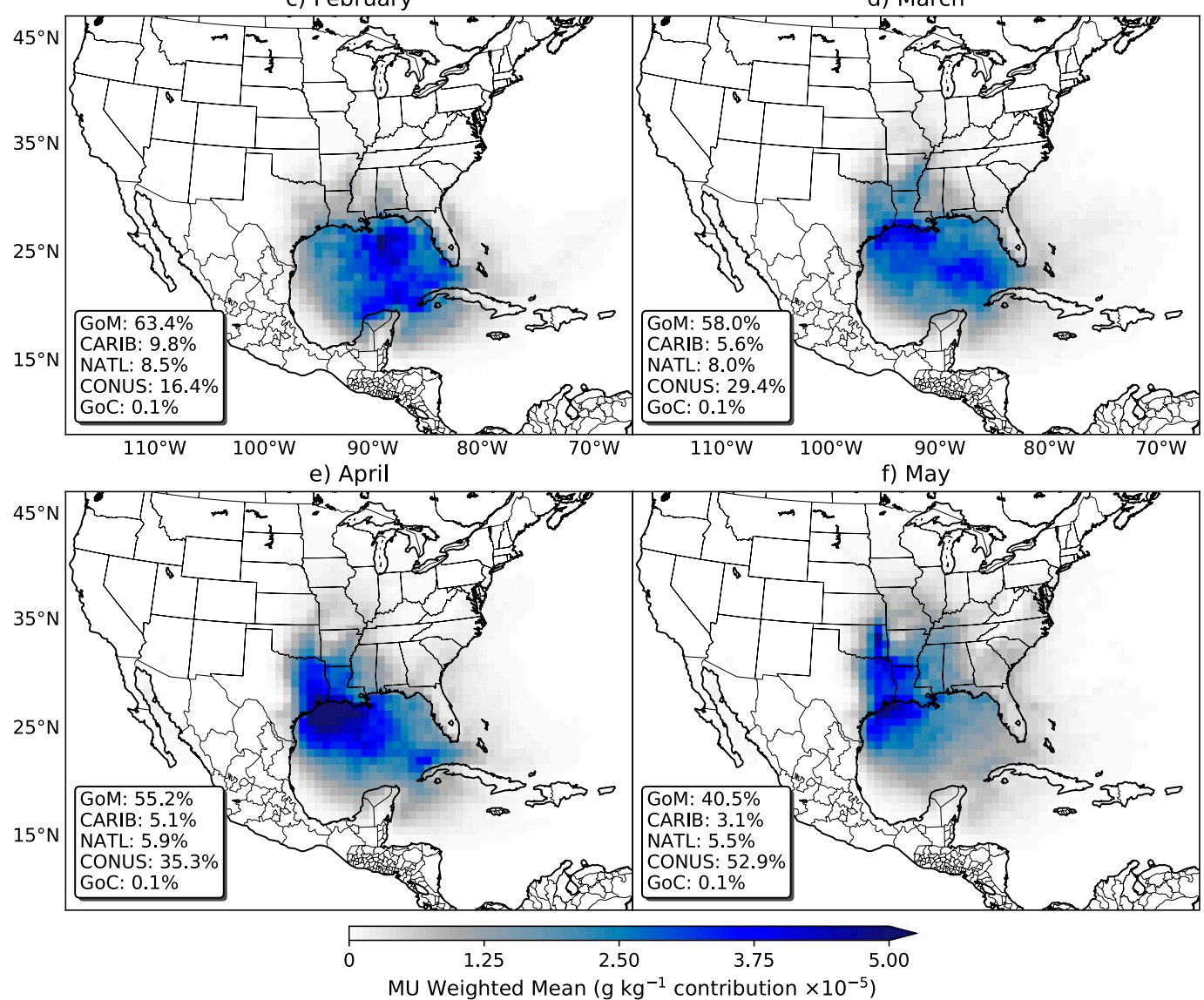

FIG. 10. Monthly MU-weighted fractional contributions of null-significant severe events (1981-2017) with percentage of MU per marine region, as delineated in Fig. 3.

far (Fig. 13). Peak moisture gains occur from within about $1500 \mathrm{~km}$ of null-severe events, with advection paths characterized by a gradual slope of vertical accent as air parcels travel to null-severe events (Fig. 13). The smooth and laminar lifting of moisture suggests that the lifting mechanism associated with null-severe events is isentropic in nature (e.g., frontal). Overall, moisture for null-severe events is generally from surficial sources at a distance of $>500 \mathrm{~km}$ and increasingly from elevated sources in closer proximity to events, likely as air parcels interact with precipitation near the apex of lifting. The precipitation may be stratiform in nature, which can develop in relatively stable conditions, hence its presence in null-severe events and lack thereof in the other climatological groups. 


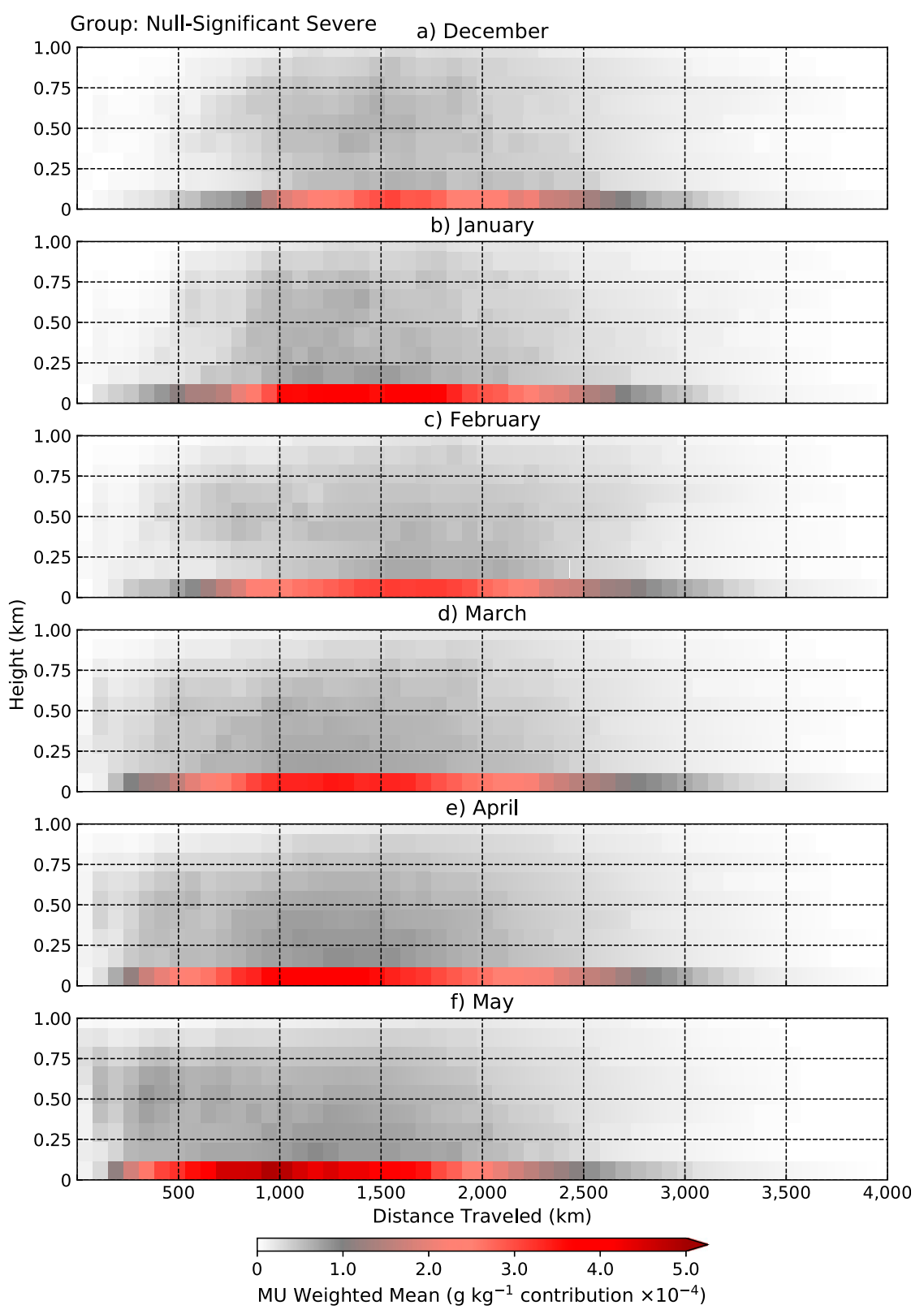

FIG. 11. Vertical cross sections of monthly MU-weighted fractional contributions of nullsignificant severe events (1981-2017). Heights are AGL.

\section{c. Relationships between moisture sources and environments}

\section{1) SEA SURFACE TEMPERATURE INFLUENCES}

Results from this study have shown that several marine basins are important contributors of moisture to tornadic and nontornadic convection. Next we explore the influence of SSTs on the water vapor content of air parcels. A bivariate Pearson correlation $r$ analysis reveals an overall positive relationship between $q$ and
SSTs preceding EF1+ tornadic convection (with mixed areas of $\alpha=0.05$ and nonsignificance; Fig. 14). These results demonstrate that warmer SSTs can lead to positive evaporative fluxes, in agreement with results from earlier studies (e.g., Stephens 1990; Stephens et al. 1993). Positive correlations are of greater magnitude in DJF as compared to MAM, suggesting that the water vapor content of air masses is more sensitive to SST magnitude during cool-season months (Figs. 14a-c). However, cool-season months are characterized by large SST fluxes associated with plunging cold fronts (Zavala-Hidalgo 
a) December
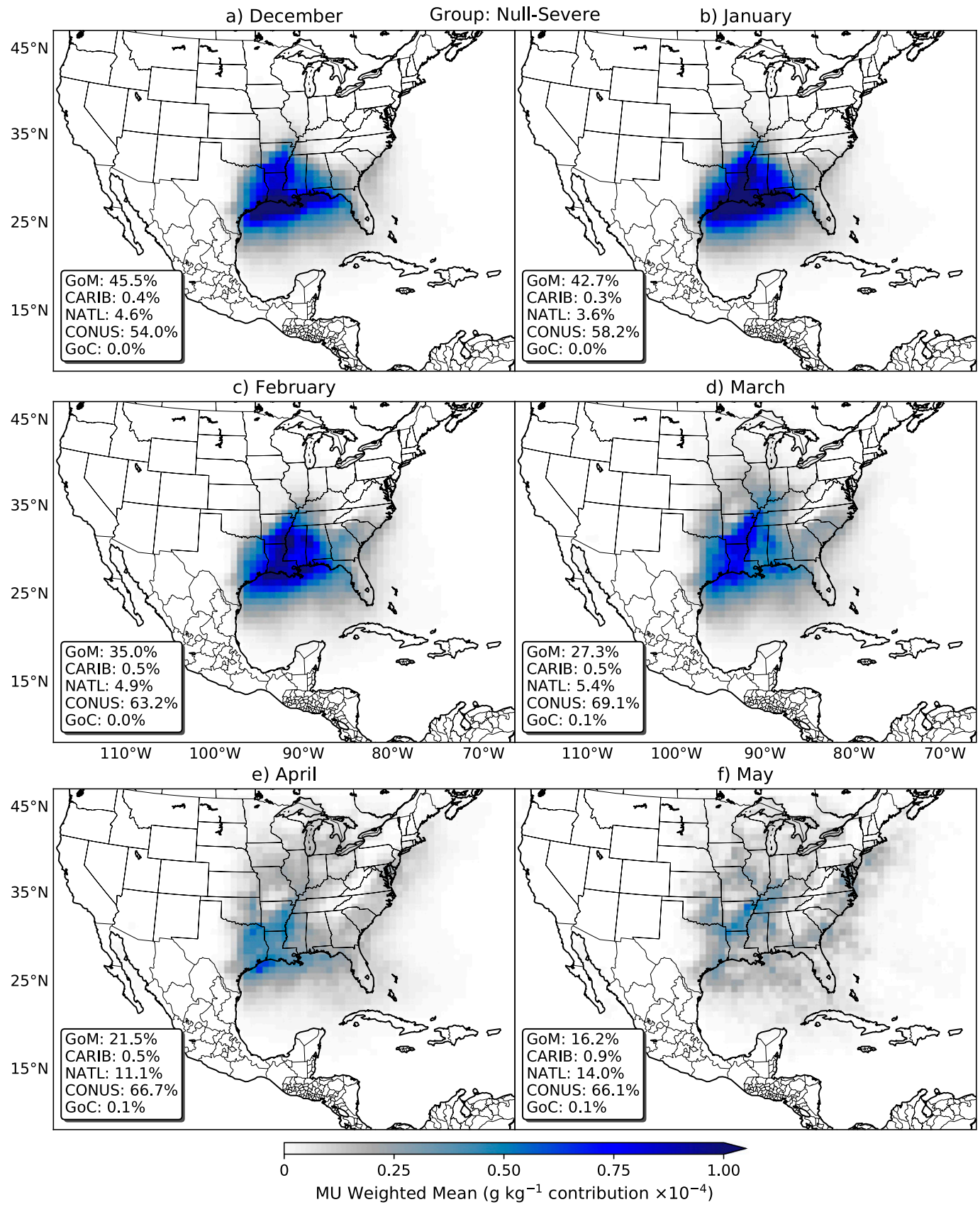

FIG. 12. Monthly MU-weighted fractional contributions of null-severe events (1981-2017) with percentage of MU per marine region, as delineated in Fig. 3.

et al. 2002). During return-flow events, continental polar air masses can acquire substantial moisture as they are advected from marine areas (e.g., GoM, CARIB) toward the CONUS, despite earlier-cooled SSTs (Lewis et al. 1989; Merrill 1992). This likely explains the small spatial areas of negative correlations across the northwestern CARIB and Yucatán Channel during DJF months $(\alpha=0.05$; Figs. 14a-c). Positive correlations across the northeastern GoM in MAM $(\alpha=0.05$; Figs. 14d-f) coincide with the LC (Vukovich 2007), which generally increases in its northern latitudinal extent in MAM (Lindo-Atichati et al. 2013). This corroborates results in Molina et al. (2016) that suggest the warm waters of the LC are a source of positive moisture flux for severe thunderstorms.

Comparison of SST and $q$ correlations of EF1+ tornadic convection to those of other tornadic climatology groups reveals no noticeable difference, with a generally 


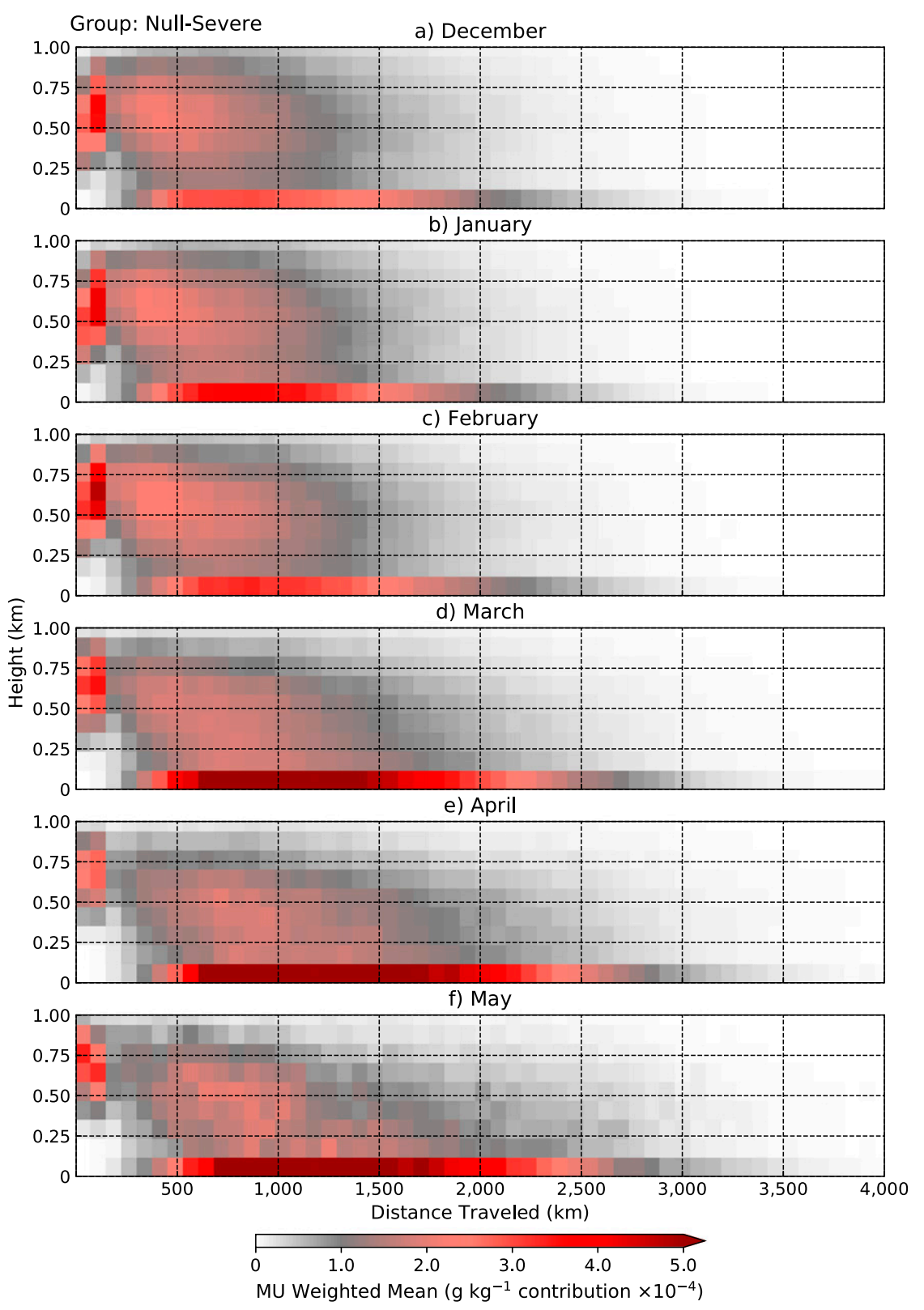

FIG. 13. Vertical cross sections of monthly MU-weighted fractional contributions of nullsevere events (1981-2017). Heights are AGL.

positive relationship between SSTs and $q$ (mixed $\alpha=$ 0.05; not shown). SSTs and $q$ of null-significant severe hail and wind reports also exhibit a positive relationship (mixed $\alpha=0.05$; not shown). When considering nullsevere events, a positive relationship between SSTs and $q$ is also observed (mixed $\alpha=0.05$; not shown), with the correlation coefficient magnitude increasing from December through May, a likely influence of SST warming driven by the seasonal cycle.

Overall, the positive correlations between SSTs and $q$ show that SSTs are an important influence on moisture loading of overlying air parcels. Warmer SSTs represent faster moving water molecules that can more easily phase change from liquid to gas, assuming all other factors remain equal. Stephens (1990) explains the thermodynamic relationship between SSTs and airmass moisture content in greater detail. However, a few caveats should be noted. This analysis does not suggest that the moisture content of an air parcel is solely dependent on the underlying SST, with water vapor fluxes also influenced by large-scale atmospheric circulation features, vertical mixing, and preexisting airmass 

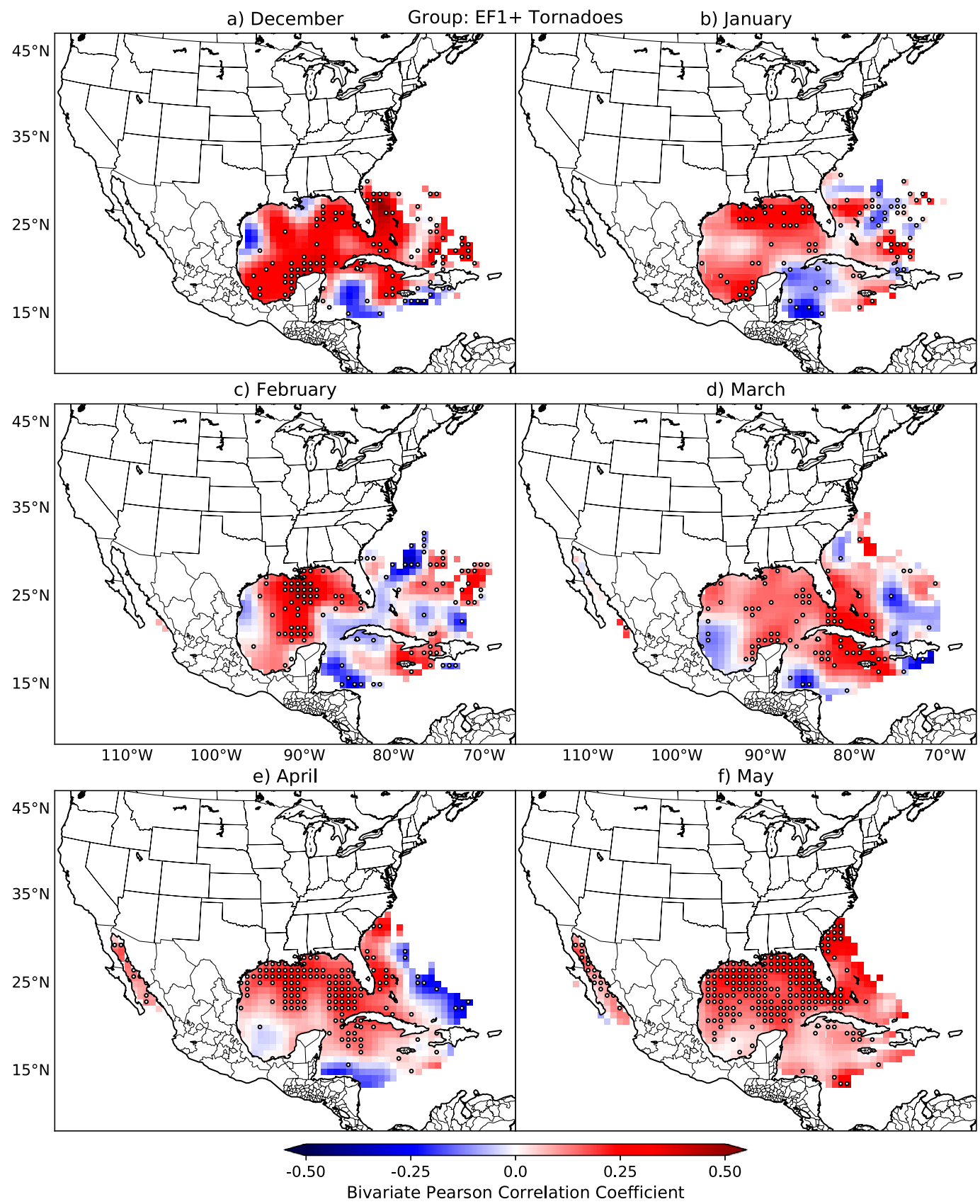

FIG. 14. Bivariate Pearson correlation coefficients for along-trajectory specific humidity $q\left(\mathrm{~g} \mathrm{~kg}^{-1}\right)$ and SSTs of surficial air parcels contributing moisture to EF1+ tornadic thunderstorms (1981-2017). Gridpoint statistical significance $(\alpha=0.05)$ indicated with stippling.

characteristics (e.g., saturation level and wind speed; Stephens 1990; Winschall et al. 2014).

\section{2) LARGE-SCALE ATMOSPHERIC INFLUENCES}

The Lagrangian-based climatology of moisture origins derived herein provides a resource to explore connections between the magnitude of meridional and zonal moisture flux and the intensity of ETCs. Overall, bivariate Pearson correlation coefficients $r$ demonstrate that as cyclone minimum pressure decreases (cyclone intensity increases), MF increases for the tornado climatology groups considered in this study (Table 2). The relationship was found statistically significant $(\alpha=0.05)$ for MF of tornado groups during the months of April and May, except for significant tornado outbreaks. This suggests that MFs of April and May tornado events 
TABLE 2. Bivariate Pearson correlation coefficient $r$ between mean horizontal moisture flux (MF; $\mathrm{m} \mathrm{s}^{-1} \mathrm{~g} \mathrm{~kg}^{-1}$ ) and extratropical cyclone (ETC) minimum pressure $(\mathrm{hPa})$ with the percentage of days that had no ETC identified, computed for MF within $24 \mathrm{~h}$ of the meteorological event. Statistically significant correlations are set in boldface $(\alpha=0.05)$. Negative (positive) values show that MF increases (decreases) as ETC minimum pressure decreases (increases).

\begin{tabular}{|c|c|c|c|c|c|c|}
\hline Trajectory group & $\operatorname{Dec}(r, \%)$ & $\operatorname{Jan}(r, \%)$ & $\operatorname{Feb}(r, \%)$ & $\operatorname{Mar}(r, \%)$ & $\operatorname{Apr}(r, \%)$ & $\operatorname{May}(r, \%)$ \\
\hline EF1+ tornadoes & $-0.20,43 \%$ & $-\mathbf{0 . 2 6}, 51 \%$ & $-0.10,41 \%$ & $-0.06,42 \%$ & $\mathbf{- 0 . 1 9}, 29 \%$ & $\mathbf{- 0 . 1 5}, 34 \%$ \\
\hline $\mathrm{EF} 2+$ tornadoes & $0.01,44 \%$ & $0.10,52 \%$ & $\mathbf{- 0 . 3 0}, 43 \%$ & $-0.10,51 \%$ & $\mathbf{- 0 . 1 7}, 36 \%$ & $-\mathbf{0 . 1 6}, 38 \%$ \\
\hline $\mathrm{EF} 1+$ tornado outbreaks & $-0.22,17 \%$ & $-0.09,33 \%$ & $-0.21,17 \%$ & $-0.10,13 \%$ & $-\mathbf{0 . 2 3}, 5 \%$ & $\mathbf{- 0 . 3 0}, 16 \%$ \\
\hline $\mathrm{EF} 2+$ tornado outbreaks & $-0.23,25 \%$ & $-0.17,35 \%$ & $0.01,0 \%$ & $-0.06,14 \%$ & $-0.17,2 \%$ & $-0.25,20 \%$ \\
\hline Null-significant hail & $-0.17,68 \%$ & $-0.17,59 \%$ & $-\mathbf{0 . 2 2}, 54 \%$ & $\mathbf{- 0 . 1 5}, 48 \%$ & $-\mathbf{0 . 2 8}, 37 \%$ & $-\mathbf{0 . 2 5}, 30 \%$ \\
\hline Null-significant wind & $-0.15,55 \%$ & $-\mathbf{0 . 3 3}, 58 \%$ & $-0.05,57 \%$ & $\mathbf{- 0 . 1 5}, 53 \%$ & $\mathbf{- 0 . 3 0}, 49 \%$ & $-\mathbf{0 . 2 0}, 37 \%$ \\
\hline
\end{tabular}

have a stronger relationship to ETCs than DJF tornado events. Null-significant severe hail and wind reports show similar results; MF is greater when ETCs are deeper (Table 2$)$ and statistically significant $(\alpha=0.05)$ during MAM. However, we note that the use of different reanalyses (e.g., NARR and ERA-Interim) may diminish the strength of the correlations between ETC minimum pressure and $\mathrm{MF}$, as there is variation in how the ETCs are depicted between these reanalyses (Hodges et al. 2011). It is also important to note that an ETC was not identified during each tornado event. Sample sizes may also influence statistical significance given that samples are larger for MAM than DJF (Table 3). Unsurprisingly, more ETCs are identified during tornado outbreaks as compared to all tornado events (Table 2). Stronger ETCs are associated with an increased potential for severe convection (e.g., Doswell and Bosart 2001; Metz et al. 2004) and are more likely to be identified by an ETC tracking algorithm (e.g., Raible et al. 2008; Neu et al. 2013). The advective winds considered in the computation of MF implicitly serve as a proxy for pressure gradient, and thus, while not explicitly computed, these results also suggest that the resultant pressure gradient between the ETC and the semipermanent high pressure to the east of the CONUS (e.g., Bermuda high) may influence the extent of MF. Future studies will explore the advective mechanisms of MF in greater depth.

The GPLLJ is climatologically favored in May (and summer months) and mostly driven by temperature differences along the east-to-west sloping terrain of the Great Plains, enhancing the transport of low-level moisture in advance of and during tornado events (Weaver and Nigam 2008; Weaver et al. 2012). Bivariate Pearson correlation coefficients $r$ reveal a positive relationship between the magnitude of the GPLLJ and MF for all tornado and null-significant severe groups, confirming that a stronger GPLLJ yields increased moisture advection ( $\alpha=0.05$; Table 4$)$. The relationship is even stronger for tornado outbreaks, which shows that stronger moisture advection and increased wind shear driven by the GPLLJ is related to more intense tornadic events $(\alpha=0.05$; Table 4$)$. There are several factors that are potentially limiting the strength of the correlations between MF and GPLLJ intensity that should be mentioned: (i) other features besides the GPLLJ can also influence advection (e.g., ETCs), (ii) the GPLLJ strength is not uniform through the depth of the lower troposphere, and (iii) the GPLLJ is not always a maximum at $925 \mathrm{hPa}$.

\section{Conclusions}

This study introduces comprehensive moisture attribution of DJF and MAM tornadic convective storms of the CONUS, conducted using HYSPLIT (Stein et al. 2015) and a Lagrangian-based algorithm (Sodemann et al. 2008). Results show that the GoM contributes more than $50 \%$ of moisture for tornadic thunderstorms during DJF and MAM, corroborating early studies that demonstrated the importance of the GoM in the CONUS water vapor budget (e.g., Hastenrath 1966; Rasmusson 1967; Molinari 1987; Hagemeyer 1991). Comparison of the moisture origins of tornado events to that of null events illustrates that contributions from the CARIB are unique to tornado-producing thunderstorms. This suggests that the inclusion of CARIB SSTs in the seasonal predictive algorithm by Elsner and Widen (2014) may not be an unreasonable choice, though the relative timing of this influence is not

TABLE 3. The sample size (number of days) of each trajectory group from Table 2 .

\begin{tabular}{lrrrrrr}
\hline \hline Trajectory group sample size & Dec & Jan & Feb & Mar & Apr & May \\
\hline EF1+ tornadoes & 135 & 151 & 146 & 310 & 458 & 653 \\
EF2+ tornadoes & 72 & 67 & 77 & 164 & 239 & 338 \\
EF1+ tornado outbreaks & 23 & 36 & 35 & 71 & 133 & 195 \\
EF2+ tornado outbreaks & 8 & 17 & 14 & 22 & 50 & 66 \\
Null-significant hail & 136 & 167 & 279 & 557 & 641 & 652 \\
Null-significant wind & 172 & 181 & 216 & 429 & 525 & 588 \\
Null-significant (combined) & 234 & 257 & 347 & 638 & 686 & 664 \\
Null-severe & 879 & 846 & 685 & 439 & 206 & 35 \\
& & & & & &
\end{tabular}


TABLE 4. Bivariate Pearson correlation coefficient $r$ between mean horizontal moisture flux (MF; $\mathrm{m} \mathrm{s}^{-1} \mathrm{~g} \mathrm{~kg}^{-1}$ ) and Great Plains low-level jet (GPLLJ) maximum meridional $v$ wind $\left(\mathrm{m} \mathrm{s}^{-1}\right)$, computed for air parcel transport up to $24 \mathrm{~h}$ before the meteorological event. Statistically significant correlations are set in boldface $(\alpha=$ $0.05)$. Positive values show that MF increases as the northerly component of the GPLLJ wind increases.

\begin{tabular}{lc}
\hline \hline Trajectory group (May) & $r$ \\
\hline EF1+ tornadoes & $\mathbf{0 . 2 2}$ \\
EF2+ tornadoes & $\mathbf{0 . 1 8}$ \\
EF1+ tornado outbreaks & $\mathbf{0 . 2 6}$ \\
EF2+ tornado outbreaks & $\mathbf{0 . 2 7}$ \\
Null-significant hail & $\mathbf{0 . 3 4}$ \\
Null-significant wind & $\mathbf{0 . 3 1}$ \\
Null-severe & 0.09 \\
\hline
\end{tabular}

pronounced for late MAM as it is for DJF. Primary results of this study follow:

1) Before tornado events, most air masses are advected across the GoM with a southerly meridional velocity vector component. Beyond the GoM, most air masses are advected with an easterly zonal velocity vector component as they cross the western CARIB and western NATL.

2) Moisture contributions to tornado events are characterized by a seasonal cycle. Aside from the GoM, DJF moisture contributions originate from the northwest CARIB $(>19 \%)$ and western NATL $(>12 \%)$, and late MAM contributions stem from continental areas of the CONUS (>24\%).

3) Water vapor contributions advected toward tornadooutbreak events (null-significant severe) are characterized by greater (less) moisture content and increased (decreased) transport distances than nonoutbreak tornado events.

4) Warmer SSTs generally result in greater air parcel moisture loading on overlying air masses. Moisture advection was found to increase when driven by more intense ETCs. Stronger GPLLJ episodes also increase the magnitude of moisture advection in May.
Accurately predicting airmass modification by the GoM during return-flow events remains challenging, with errors due in part to water vapor uncertainties in areas that lack in situ observations for assimilation into models (e.g., Lewis et al. 2016; Lakshmivarahan et al. 2017). By explicitly demarcating the moisture sources of tornadic storms, operational forecasters now can refer to specific areas to qualitatively assess the potential for positive evaporative flux on overlying air masses. The disparities between the moisture sources of tornadic events and null events also shed light into the physical processes that drive moisture fluxes for different classes of convective events. This study also provides SST and soil moisture regions of interest that could be used as predictors in subseasonal-to-seasonal forecasts of severe convective storms (Allen et al. 2015; Lepore et al. 2017). However, moisture sources could be sensitive to the length of the trajectories and the spatial domain of the tornado climatology considered (e.g., Brooks et al. 2003; Marsh and Brooks 2012), topics that will be explored in follow-up work. We also note that some moisture fluxes are not accounted for using the Sodemann et al. (2008) algorithm (Table 5), which are limitations related to the $\Delta q$ and HPBL thresholds. Improvements to moisture uptake diagnostics are planned.

It is possible that moisture sources are modulated by external climate influences that impact tornado frequency (Tippett et al. 2015), such as El Niño-Southern Oscillation (Allen et al. 2015, 2018), the Madden-Julian oscillation (Thompson and Roundy 2013; Tippett 2018), and Arctic sea ice extent (Trapp and Hoogewind 2018). Forthcoming work will explore the influence of modulated climate base states on moisture sources and advection patterns. When considering longer climate scales, the origins and transport patterns of water vapor may already be undergoing changes because of global warming (Trenberth 1998; Trenberth et al. 2011; Allen 2018), which emphasizes the importance of better understanding the hydrological cycle as it relates to convection. By broadening our understanding of the physical processes driving moisture fluxes, this study provides a

TABLE 5. Estimate of the percent of $\Delta q$ explained by the MU diagnostic, which involved two computations: (i) percent $\Delta q$ exceeding $\pm 0.2 \mathrm{~g} \mathrm{~kg}^{-1}$ every $6 \mathrm{~h}$ and (ii) percent $\Delta q+0.2 \mathrm{~g} \mathrm{~kg}^{-1}$ below the HPBL every $6 \mathrm{~h}$.

\begin{tabular}{|c|c|c|c|c|c|c|}
\hline MU explained & $\operatorname{Dec}(\mathrm{i}, \mathrm{ii})$ & Jan (i, ii) & Feb (i, ii) & Mar (i, ii) & Apr (i, ii) & May (i, ii) \\
\hline EF1+ tornadoes & $77 \%, 48 \%$ & $78 \%, 46 \%$ & $77 \%, 45 \%$ & $77 \%, 49 \%$ & $78 \%, 44 \%$ & $79 \%, 46 \%$ \\
\hline $\mathrm{EF} 2+$ tornadoes & $79 \%, 40 \%$ & $79 \%, 42 \%$ & $78 \%, 44 \%$ & $78 \%, 48 \%$ & $78 \%, 43 \%$ & $79 \%, 49 \%$ \\
\hline EF1+ tornado outbreaks & $78 \%, 36 \%$ & $79 \%, 40 \%$ & $78 \%, 42 \%$ & $78 \%, 46 \%$ & $78 \%, 40 \%$ & $80 \%, 44 \%$ \\
\hline $\mathrm{EF} 2+$ tornado outbreaks & $78 \%, 37 \%$ & $78 \%, 38 \%$ & $78 \%, 38 \%$ & $78 \%, 44 \%$ & $78 \%, 42 \%$ & $78 \%, 44 \%$ \\
\hline Null-significant hail & $77 \%, 54 \%$ & $76 \%, 55 \%$ & $75 \%, 52 \%$ & $74 \%, 52 \%$ & $76 \%, 49 \%$ & $78 \%, 45 \%$ \\
\hline Null-significant wind & $76 \%, 46 \%$ & $77 \%, 48 \%$ & $75 \%, 47 \%$ & $75 \%, 46 \%$ & $76 \%, 45 \%$ & $79 \%, 42 \%$ \\
\hline Null-severe & $65 \%, 41 \%$ & $61 \%, 41 \%$ & $62 \%, 41 \%$ & $60 \%, 46 \%$ & $61 \%, 47 \%$ & $67 \%, 43 \%$ \\
\hline
\end{tabular}


baseline against which to test future model projections of the water vapor budget associated with convective storms.

Acknowledgments. M. J. Molina was supported by the Earth and Ecosystem Science doctoral program at Central Michigan University. The authors recognize the NOAA Air Resources Laboratory as an invaluable resource in this work, providing the HYSPLIT model and training. Patrick Marsh from NOAA's Storm Prediction Center provided preliminary 2017 tornado report data. The authors also thank Michael Sprenger from the Institute for Atmosphere and Climate Science at ETH Zürich for provision of cyclone track data.

\section{REFERENCES}

Allen, J. T., 2018: Climate change and severe thunderstorms. $O x$ ford Research Encyclopedia of Climate Science, Oxford University Press, https://doi.org/10.1093/acrefore/9780190228620. 013.62.

_, M. K. Tippett, and A. H. Sobel, 2015: Influence of the El Niño/Southern Oscillation on tornado and hail frequency in the United States. Nat. Geosci., 8, 278-283, https://doi.org/ 10.1038/ngeo2385.

_ - M. J. Molina, and V. A. Gensini, 2018: Modulation of annual cycle of tornadoes by El Niño-Southern Oscillation. Geophys. Res. Lett., 45, 5708-5717, https://doi.org/10.1029/2018GL077482.

Angevine, W. M., and K. Mitchell, 2001: Evaluation of the NCEP mesoscale Eta model convective boundary layer for air quality applications. Mon. Wea. Rev., 129, 2761-2775, https://doi.org/ 10.1175/1520-0493(2001)129<2761:EOTNME > 2.0.CO;2.

Baldini, L. M., F. McDermott, J. U. Baldini, M. J. Fischer, and M. Möllhoff, 2010: An investigation of the controls on Irish precipitation $\delta^{18} \mathrm{O}$ values on monthly and event timescales. Climate Dyn., 35, 977-993, https://doi.org/10.1007/s00382-0100774-6.

Banacos, P. C., and D. M. Schultz, 2005: The use of moisture flux convergence in forecasting convective initiation: Historical and operational perspectives. Wea. Forecasting, 20, 351-366, https://doi.org/10.1175/WAF858.1.

Blender, R., K. Fraedrich, and F. Lunkeit, 1997: Identification of cyclone-track regimes in the North Atlantic. Quart. J. Roy. Meteor. Soc., 123, 727-741, https://doi.org/10.1002/qj.49712353910.

Bohlinger, P., A. Sorteberg, and H. Sodemann, 2017: Synoptic conditions and moisture sources actuating extreme precipitation in Nepal. J. Geophys. Res. Atmos., 122, $12653-12671$, https://doi.org/10.1002/2017JD027543.

,-- C. Liu, R. Rasmussen, H. Sodemann, and F. Ogawa, 2018: Multiscale characteristics of an extreme precipitation event over Nepal. Quart. J. Roy. Meteor. Soc., 145, 179-196, https://doi.org/10.1002/qj.3418.

Brooks, H. E., C. A. Doswell III, and M. P. Kay, 2003: Climatological estimates of local daily tornado probability for the United States. Wea. Forecasting, 18, 626-640, https://doi.org/ 10.1175/1520-0434(2003)018<0626:CEOLDT $>2.0$.CO;2.

, A. R. Anderson, K. Riemann, I. Ebbers, and H. Flachs, 2007: Climatological aspects of convective parameters from the NCAR/NCEP reanalysis. Atmos. Res., 83, 294-305, https:// doi.org/10.1016/j.atmosres.2005.08.005.
_ , G. W. Carbin, and P. T. Marsh, 2014: Increased variability of tornado occurrence in the United States. Science, 346, 349352, https://doi.org/10.1126/science.1257460.

Childs, S. J., R. S. Schumacher, and J. T. Allen, 2018: Cold-season tornadoes: Climatological and meteorological insights. Wea. Forecasting, 33, 671-691, https://doi.org/10.1175/WAF-D-170120.1.

Clark, C. A., and P. W. Arritt, 1995: Numerical simulations of the effect of soil moisture and vegetation cover on the development of deep convection. J. Appl. Meteor., 34, 20292045, https://doi.org/10.1175/1520-0450(1995)034<2029: NSOTEO $>2.0 . \mathrm{CO} ; 2$.

Coffer, B. E., and M. D. Parker, 2017: Simulated supercells in nontornadic and tornadic VORTEX2 environments. Mon. Wea. Rev., 145, 149-180, https://doi.org/10.1175/MWR-D-160226.1 .

Cook, A. R., L. M. Leslie, D. B. Parsons, and J. T. Schaefer, 2017: The impact of the El Niño-Southern Oscillation (ENSO) on winter and early spring US tornado outbreaks. J. Appl. Meteor. Climatol., 56, 2455-2478, https://doi.org/10.1175/JAMCD-16-0249.1.

Dee, D. P., and Coauthors, 2011: The ERA-Interim reanalysis: Configuration and performance of the data assimilation system. Quart. J. Roy. Meteor. Soc., 137, 553-597, https://doi.org/ 10.1002/qj.828.

De Leeuw, J., J. Methven, and M. Blackburn, 2017: Physical factors influencing regional precipitation variability attributed using an airmass trajectory method. J. Climate, 30, 7359-7378, https://doi.org/10.1175/JCLI-D-16-0547.1.

Doswell, C. A., III, 1987: The distinction between large-scale and mesoscale contribution to severe convection: A case study example. Wea. Forecasting, 2, 3-16, https://doi.org/10.1175/ 1520-0434(1987)002<0003:TDBLSA >2.0.CO;2.

— , and L. F. Bosart, 2001: Extratropical synoptic-scale processes and severe convection. Severe Convective Storms, Meteor. Monogr., No. 50, Amer. Meteor. Soc., 27-69.

- H. E. Brooks, and R. A. Maddox, 1996: Flash flood forecasting: An ingredients-based methodology. Wea. Forecasting, 11, 560-581, https://doi.org/10.1175/1520-0434(1996)011<0560: FFFAIB $>2.0 . \mathrm{CO} ; 2$

— , R. Edwards, R. Thompson, J. Hart, and K. Crosbie, 2006: A simple and flexible method for ranking severe weather events. Wea. Forecasting, 21, 939-951, https://doi.org/10.1175/ WAF959.1.

, H. E. Brooks, and N. Dotzek, 2009: On the implementation of the enhanced Fujita scale in the USA. Atmos. Res., 93, 554563, https://doi.org/10.1016/j.atmosres.2008.11.003.

Draxler, R., B. Stunder, G. Rolph, A. Stein, and A. Taylor, 2016: HYSPLIT4 user's guide version 4. NOAA Air Resources Laboratory, 254 pp., https://www.arl.noaa.gov/documents/ reports/hysplit_user_guide.pdf.

Edwards, R., and S. J. Weiss, 1996: Comparisons between Gulf of Mexico sea surface temperature anomalies and southern U.S. severe thunderstorm frequency in the cool season. 18th Conf. on Severe Local Storms, San Francisco, CA, Amer. Meteor. Soc., 19-23.

, J. G. LaDue, J. T. Ferree, K. Scharfenberg, C. Maier, and W. L. Coulbourne, 2013: Tornado intensity estimation: Past, present, and future. Bull. Amer. Meteor. Soc., 94, 641-653, https://doi.org/10.1175/BAMS-D-11-00006.1.

Eichler, T., and W. Higgins, 2006: Climatology and ENSO-related variability of North American extratropical cyclone activity. J. Climate, 19, 2076-2093, https://doi.org/10.1175/JCLI3725.1. 
Elsner, J. B., and H. M. Widen, 2014: Predicting spring tornado activity in the central Great Plains by 1 March. Mon. Wea. Rev., 142, 259-267, https://doi.org/10.1175/MWR-D-1300014.1.

Fuhrmann, C. M., C. E. Konrad, M. M. Kovach, J. T. McLeod, W. G. Schmitz, and P. G. Dixon, 2014: Ranking of tornado outbreaks across the United States and their climatological characteristics. Wea. Forecasting, 2, 684-701, https://doi.org/ 10.1175/WAF-D-13-00128.1.

Fujita, T. T., 1971: Proposed characterization of tornadoes and hurricanes by area and intensity. University of Chicago SMRP Research Paper 91, 42 pp.

Galway, J. G., 1979: Relationship between precipitation and tornado activity. J. Amer. Water Resour. Assoc., 15, 961-964, https://doi.org/10.1029/WR015i004p00961.

Gebauer, J. G., A. Shapiro, E. Fedorovich, and P. Klein, 2018: Convection initiation caused by heterogeneous low-level jets over the Great Plains. Mon. Wea. Rev., 146, 2615-2637, https:// doi.org/10.1175/MWR-D-18-0002.1.

Gensini, V. A., T. L. Mote, and H. E. Brooks, 2014: Severe-thunderstorm reanalysis environments and collocated radiosonde observations. J. Appl. Meteor. Climatol., 53, 742-751, https:// doi.org/10.1175/JAMC-D-13-0263.1.

Gimeno, L., and Coauthors, 2012: Oceanic and terrestrial sources of continental precipitation. Rev. Geophys., 50, RG4003, https://doi.org/10.1029/2012RG000389.

Gustafsson, M., D. Rayner, and D. Chen, 2010: Extreme rainfall events in southern Sweden: Where does the moisture come from? Tellus, 62A, 605-616, https://doi.org/10.1111/j.16000870.2010.00456.x.

Hagemeyer, B. C., 1991: A lower-tropospheric thermodynamic climatology for March through September: Some implications for thunderstorm forecasting. Wea. Forecasting, 6, 254-270, https:// doi.org/10.1175/1520-0434(1991)006<0254:ALTTCF >2.0.CO;2.

Hastenrath, S. L., 1966: The flux of atmospheric water vapor over the Caribbean Sea and the Gulf of Mexico. J. Appl. Meteor., 5, 778-788, https://doi.org/10.1175/1520-0450(1966)005<0778: TFOAWV $>2.0 . \mathrm{CO} ; 2$.

Hawcroft, M., L. Shaffrey, K. Hodges, and H. Dacre, 2012: How much Northern Hemisphere precipitation is associated with extratropical cyclones? Geophys. Res. Lett., 39, L24809, https://doi.org/10.1029/2012GL053866.

Helfand, H. M., and S. D. Schubert, 1995: Climatology of the simulated Great Plains low-level jet and its contribution to the continental moisture budget of the United States. J. Climate, $\mathbf{8}$, 784-806, https://doi.org/10.1175/1520-0442(1995)008<0784: COTSGP $>2.0 . \mathrm{CO} ; 2$.

Higgins, R., Y. Yao, E. Yarosh, J. E. Janowiak, and K. Mo, 1997: Influence of the Great Plains low-level jet on summertime precipitation and moisture transport over the central United States. J. Climate, 10, 481-507, https://doi.org/10.1175/15200442(1997)010<0481:IOTGPL>2.0.CO;2.

Hodges, K. I., R. W. Lee, and L. Bengtsson, 2011: A comparison of extratropical cyclones in recent reanalyses ERA-Interim, NASA MERRA, NCEP CFSR, and JRA-25. J. Climate, 24, 4888-4906, https://doi.org/10.1175/2011JCLI4097.1.

Holton, J. R., and G. J. Hakim, 2012: An Introduction to Dynamic Meteorology. International Geophysics Series, Vol. 88, Academic Press, 552 pp.

Huang, B., and Coauthors, 2017: Extended Reconstructed Sea Surface Temperature, version 5 (ERSSTv5): Upgrades, validations, and intercomparisons. J. Climate, 30, 8179-8205, https://doi.org/10.1175/JCLI-D-16-0836.1.
Hunter, J. D., 2007: Matplotlib: A 2D graphics environment. Comput. Sci. Eng., 9, 90-95, https://doi.org/10.1109/MCSE. 2007.55.

Jana, S., B. Rajagopalan, M. A. Alexander, and A. J. Ray, 2018: Understanding the dominant sources and tracks of moisture for summer rainfall in the southwest United States. J. Geophys. Res. Atmos., 123, 4850-4870, https://doi.org/10. 1029/2017JD027652.

Janjić, Z., 1996: The Mellor-Yamada level-2.5 scheme in the NCEP Eta model. Preprints, 11th Conf. on Numerical Weather Prediction, Norfolk, VA, Amer. Meteor. Soc., 333-334.

Jung, E., and B. P. Kirtman, 2016: Can we predict seasonal changes in high impact weather in the United States? Environ. Res. Lett., 11, 074018, https://doi.org/10.1088/1748-9326/11/7/ 074018.

King, J. R., M. D. Parker, K. D. Sherburn, and G. M. Lackmann, 2017: Rapid evolution of cool season, low-CAPE severe thunderstorm environments. Wea. Forecasting, 32, 763-779, https://doi.org/10.1175/WAF-D-16-0141.1.

Klees, A. M., Y. P. Richardson, P. M. Markowski, C. Weiss, J. M. Wurman, and K. K. Kosiba, 2016: Comparison of the tornadic and nontornadic supercells intercepted by VORTEX2 on 10 June 2010. Mon. Wea. Rev., 144, 3201-3231, https://doi.org/ 10.1175/MWR-D-15-0345.1.

Krishnamurthy, L., G. A. Vecchi, R. Msadek, A. Wittenberg, T. L. Delworth, and F. Zeng, 2015: The seasonality of the Great Plains low-level jet and ENSO relationship. J. Climate, 28, 4525-4544, https://doi.org/10.1175/JCLI-D-14-00590.1.

Krocak, M. J., and H. E. Brooks, 2018: Climatological estimates of hourly tornado probability for the United States. Wea. Forecasting, 33, 59-69, https://doi.org/10.1175/WAF-D-17-0123.1.

Kurita, N., 2011: Origin of Arctic water vapor during the icegrowth season. Geophys. Res. Lett., 38, L02709, https://doi.org/ 10.1029/2010GL046064.

Läderach, A., and H. Sodemann, 2016: A revised picture of the atmospheric moisture residence time. Geophys. Res. Lett., 43, 924-933, https://doi.org/10.1002/2015GL067449.

Lakshmivarahan, S., J. M. Lewis, and R. Jabrzemski, 2017: The Gulf of Mexico problem: Return flow analysis. Forecast Error Correction Using Dynamic Data Assimilation, Springer, 149-205.

Lee, S.-K., A. T. Wittenberg, D. B. Enfield, S. J. Weaver, C. Wang, and R. Atlas, 2016: US regional tornado outbreaks and their links to spring ENSO phases and North Atlantic SST variability. Environ. Res. Lett., 11, 044008, https://doi.org/10.1088/ 1748-9326/11/4/044008.

Lepore, C., M. K. Tippett, and J. T. Allen, 2017: ENSO-based probabilistic forecasts of March-May US tornado and hail activity. Geophys. Res. Lett., 44, 9093-9101, https://doi.org/ 10.1002/2017GL074781.

Lewis, J. M., C. M. Hayden, R. T. Merrill, and J. M. Schneider, 1989: GUFMEX: A study of return flow in the Gulf of Mexico. Bull. Amer. Meteor. Soc., 70, 24-29, https://doi.org/10.1175/ 1520-0477(1989)070<0024:GASORF $>2.0$.CO;2.

_, S. Lakshmivarahan, J. Hu, R. Edwards, R. A. Maddox, R. L. Thompson, and S. F. Corfidi, 2016: Ensemble forecasting of return flow over the Gulf of Mexico. Electron. J. Severe Storms Meteor., 11 (4), http://www.ejssm.org/ojs/index.php/ejssm/ article/viewArticle/155.

Liang, Y.-C., J.-Y. Yu, M.-H. Lo, and C. Wang, 2015: The changing influence of El Niño on the Great Plains low-level jet. Atmos. Sci. Lett., 16, 512-517, https://doi.org/10.1002/asl.590.

Lindo-Atichati, D., F. Bringas, and G. Goni, 2013: Loop Current excursions and ring detachments during 1993-2009. Int. 
J. Remote Sens., 34, 5042-5053, https://doi.org/10.1080/ 01431161.2013.787504.

Marsh, P. T., and H. E. Brooks, 2012: Comments on "Tornado risk analysis: Is Dixie Alley an extension of Tornado Alley?" Bull. Amer. Meteor. Soc., 93, 405-407, https://doi.org/10.1175/ BAMS-D-11-00219.1.

McDonald, J. R., and K. C. Mehta, 2006: A recommendation for an Enhanced Fujita scale (EF-Scale), revision 2. Wind Science and Engineering Center, Texas Tech University, 95 pp., http:// www.depts.ttu.edu/nwi/pubs/fscale/efscale.pdf.

Mercer, A. E., C. M. Shafer, C. A. Doswell III, L. M. Leslie, and M. B. Richman, 2009: Objective classification of tornadic and nontornadic severe weather outbreaks. Mon. Wea. Rev., 137, 4355-4368, https://doi.org/10.1175/2009MWR2897.1.

Merrill, R. T., 1992: Synoptic analysis of the GUFMEX return-flow event of 10-12 March 1988. J. Appl. Meteor., 31, 849-867, https:// doi.org/10.1175/1520-0450(1992)031<0849:SAOTGR > 2.0.CO;2.

Mesinger, F., and Coauthors, 2006: North American Regional Reanalysis. Bull. Amer. Meteor. Soc., 87, 343-360, https:// doi.org/10.1175/BAMS-87-3-343.

Mestas-Nuñez, A. M., C. Zhang, and D. B. Enfield, 2005: Uncertainties in estimating moisture fluxes over the IntraAmericas Sea. J. Hydrometeor., 6, 696-709, https://doi.org/ 10.1175/JHM442.1.

_ D. B. Enfield, and C. Zhang, 2007: Water vapor fluxes over the Intra-Americas Sea: Seasonal and interannual variability and associations with rainfall. J. Climate, 20, 1910-1922, https://doi.org/10.1175/JCLI4096.1.

Metz, N. D., D. M. Schultz, and R. H. Johns, 2004: Extratropical cyclones with multiple warm-front-like baroclinic zones and their relationship to severe convective storms. Wea. Forecasting, 19, 907-916, https://doi.org/10.1175/1520-0434(2004) 019<0907:ECWMWB > 2.0.CO;2.

Molina, M. J., R. P. Timmer, and J. T. Allen, 2016: Importance of the Gulf of Mexico as a climate driver for U.S. severe thunderstorm activity. Geophys. Res. Lett., 43, 12 295-12 304, https://doi.org/10.1002/2016GL071603.

, J. T. Allen, and V. A. Gensini, 2018: The Gulf of Mexico and ENSO influence on subseasonal and seasonal CONUS winter tornado variability. J. Appl. Meteor. Climatol., 57, 2439-2463, https://doi.org/10.1175/JAMC-D-18-0046.1.

Molinari, R. L., 1987: Air mass modification over the eastern Gulf of Mexico as a function of surface wind fields and Loop Current position. Mon. Wea. Rev., 115, 646-652, https://doi.org/ 10.1175/1520-0493(1987)115<0646:AMMOTE > 2.0.CO;2.

Muñoz, E., and D. Enfield, 2011: The boreal spring variability of the Intra-Americas low-level jet and its relation with precipitation and tornadoes in the eastern United States. Climate Dyn., 36, 247-259, https://doi.org/10.1007/s00382-009-0688-3.

Murray, R. J., and I. Simmonds, 1991: A numerical scheme for tracking cyclone centres from digital data. Part I: Development and operation of the scheme. Aust. Meteor. Mag., 39, 155-166.

Neu, U., and Coauthors, 2013: IMILAST: A community effort to intercompare extratropical cyclone detection and tracking algorithms. Bull. Amer. Meteor. Soc., 94, 529-547, https:// doi.org/10.1175/BAMS-D-11-00154.1.

Pfahl, S., and H. Wernli, 2008: Air parcel trajectory analysis of stable isotopes in water vapor in the eastern Mediterranean. J. Geophys. Res., 113, D20104, https://doi.org/10.1029/ 2008JD009839.

- E. Madonna, M. Boettcher, H. Joos, and H. Wernli, 2014 Warm conveyor belts in the ERA-Interim dataset (19792010). Part II: Moisture origin and relevance for precipitation.
J. Climate, 27, 27-40, https://doi.org/10.1175/JCLI-D-1300223.1.

Raible, C., P. Della-Marta, C. Schwierz, H. Wernli, and R. Blender, 2008: Northern Hemisphere extratropical cyclones: A comparison of detection and tracking methods and different reanalyses. Mon. Wea. Rev., 136, 880-897, https://doi.org/ 10.1175/2007MWR2143.1.

Rasmussen, E. N., and D. O. Blanchard, 1998: A baseline climatology of sounding-derived supercell and tornado forecast parameters. Wea. Forecasting, 13, 1148-1164, https://doi.org/ 10.1175/1520-0434(1998)013<1148:ABCOSD>2.0.CO;2.

Rasmusson, E. M., 1967: Atmospheric water vapor transport and the water balance of North America: Part I. Characteristics of the water vapor flux field. Mon. Wea. Rev., 95, 403427, https://doi.org/10.1175/1520-0493(1967)095<0403: AWVTAT $>2.3 . \mathrm{CO} ; 2$

_ 1971: A study of the hydrology of eastern North America using atmospheric vapor flux data. Mon. Wea. Rev., 99, 19-135, https:// doi.org/10.1175/1520-0493(1971)099<0119:ASOTHO>2.3.CO;2.

Reynolds, R. W., T. M. Smith, C. Liu, D. B. Chelton, K. S. Casey, and M. G. Schlax, 2007: Daily high-resolution-blended analyses for sea surface temperature. J. Climate, 20, 5473-5496, https://doi.org/10.1175/2007JCLI1824.1.

Schaefer, J. T., and R. Edwards, 1999: The SPC tornado/severe thunderstorm database. Preprints, 11th Conf. Applied Climatology, Dallas, TX, Amer. Meteor. Soc., 215-220.

- R. S. Schneider, and M. P. Kay, 2002: The robustness of tornado hazard estimates. Third Symp. on Environmental Applications, Orlando, FL, Amer. Meteor. Soc., 4.2, https:// ams.confex.com/ams/pdfpapers/27694.pdf.

Schmid, P., and D. Niyogi, 2012: A method for estimating planetary boundary layer heights and its application over the ARM Southern Great Plains site. J. Atmos. Oceanic Technol., 29, 316-322, https://doi.org/10.1175/JTECH-D-11-00118.1.

Sheffield, J., B. Livneh, and E. F. Wood, 2012: Representation of terrestrial hydrology and large-scale drought of the continental United States from the North American Regional Reanalysis. J. Hydrometeor., 13, 856-876, https://doi.org/ 10.1175/JHM-D-11-065.1.

Sherburn, K. D., and M. D. Parker, 2014: Climatology and ingredients of significant severe convection in high-shear, lowCAPE environments. Wea. Forecasting, 29, 854-877, https:// doi.org/10.1175/WAF-D-13-00041.1.

- _ - J. R. King, and G. M. Lackmann, 2016: Composite environments of severe and non-severe high-shear, lowCAPE convective events. Wea. Forecasting, 31, 1899-1927, https://doi.org/10.1175/WAF-D-16-0086.1.

Sjostrom, D. J., and J. M. Welker, 2009: The influence of air mass source on the seasonal isotopic composition of precipitation, eastern USA. J. Geochem. Explor., 102, 103-112, https:// doi.org/10.1016/j.gexplo.2009.03.001.

Smith, B. T., R. L. Thompson, J. S. Grams, C. Broyles, and H. E. Brooks, 2012: Convective modes for significant severe thunderstorms in the contiguous United States. Part I: Storm classification and climatology. Wea. Forecasting, 27, 11141135, https://doi.org/10.1175/WAF-D-11-00115.1.

Sodemann, H., C. Schwierz, and H. Wernli, 2008: Interannual variability of Greenland winter precipitation sources: Lagrangian moisture diagnostic and North Atlantic Oscillation influence. J. Geophys. Res., 113, D03107, https://doi.org/ 10.1029/2007JD008503.

Sprenger, M., and Coauthors, 2017: Global climatologies of Eulerian and Lagrangian flow features based on ERA-Interim. 
Bull. Amer. Meteor. Soc., 98, 1739-1748, https://doi.org/ 10.1175/BAMS-D-15-00299.1.

Stein, A., R. R. Draxler, G. D. Rolph, B. J. Stunder, M. Cohen, and F. Ngan, 2015: NOAA's HYSPLIT atmospheric transport and dispersion modeling system. Bull. Amer. Meteor. Soc., 96, 2059-2077, https://doi.org/10.1175/BAMS-D-14-00110.1.

Stephens, G. L., 1990: On the relationship between water vapor over the oceans and sea surface temperature. J. Climate, $\mathbf{3}$, 634-645, https://doi.org/10.1175/1520-0442(1990)003<0634: OTRBWV $>2.0 . \mathrm{CO} ; 2$.

, D. A. Randall, I. L. Wittmeyer, D. A. Dazlich, and S. Tjemkes, 1993: The Earth's radiation budget and its relation to atmospheric hydrology: 3. Comparison of observations over the oceans with a GCM. J. Geophys. Res., 98, 4931-4950, https://doi.org/10.1029/92JD02520.

Stohl, A., 1998: Computation, accuracy and applications of trajectories-A review and bibliography. Atmos. Environ., 32, 947-966, https://doi.org/10.1016/S1352-2310(97)00457-3.

_, and P. James, 2004: A Lagrangian analysis of the atmospheric branch of the global water cycle. Part I: Method description, validation, and demonstration for the August 2002 flooding in central Europe. J. Hydrometeor., 5, 656-678, https://doi.org/ 10.1175/1525-7541(2004)005<0656:ALAOTA $>2.0 . \mathrm{CO} ; 2$.

Thompson, D. B., and P. E. Roundy, 2013: The relationship between the Madden-Julian oscillation and U.S. violent tornado outbreaks in the spring. Mon. Wea. Rev., 141, 2087-2095, https://doi.org/10.1175/MWR-D-12-00173.1.

Thompson, R. L., R. Edwards, J. A. Hart, K. L. Elmore, and P. Markowski, 2003: Close proximity soundings within supercell environments obtained from the Rapid Update Cycle. Wea. Forecasting, 18, 1243-1261, https://doi.org/10.1175/15200434(2003)018<1243:CPSWSE $>2.0$. CO;2.

, B. T. Smith, J. S. Grams, A. R. Dean, and C. Broyles, 2012: Convective modes for significant severe thunderstorms in the contiguous United States. Part II: Supercell and QLCS tornado environments. Wea. Forecasting, 27, 1136-1154, https:// doi.org/10.1175/WAF-D-11-00116.1.

Tippett, M. K., 2018: Robustness of relations between the MJO and US tornado occurrence. Mon. Wea. Rev., 146, 3873-3884, https://doi.org/10.1175/MWR-D-18-0207.1.

$\longrightarrow$, J. T. Allen, V. A. Gensini, and H. E. Brooks, 2015: Climate and hazardous convective weather. Curr. Climate Change Rep., 1, 60-73, https://doi.org/10.1007/s40641-015-0006-6.

— C. Lepore, and J. E. Cohen, 2016: More tornadoes in the most extreme U.S. tornado outbreaks. Science, 354, 1419-1423, https://doi.org/10.1126/science.aah7393.

Trapp, R. J., and K. A. Hoogewind, 2018: Exploring a possible connection between U.S. tornado activity and Arctic sea ice. npj Climate Atmos. Science, 1, 14, https://doi.org/10.1038/ s41612-018-0025-9.

Trenberth, K. E., 1997: Using atmospheric budgets as a constraint on surface fluxes. J. Climate, 10, 2796-2809, https://doi.org/ 10.1175/1520-0442(1997)010<2796:UABAAC > 2.0.CO;2.

_ 1998 : Atmospheric moisture residence times and cycling: Implications for rainfall rates and climate change. Climatic Change, 39, 667-694, https://doi.org/10.1023/A:1005319109110.

_, J. T. Fasullo, and J. Mackaro, 2011: Atmospheric moisture transports from ocean to land and global energy flows in reanalyses. J. Climate, 24, 4907-4924, https://doi.org/10.1175/ 2011JCLI4171.1.

Verbout, S. M., H. E. Brooks, L. M. Leslie, and D. M. Schultz, 2006: Evolution of the U.S. tornado database: 1954-2003. Wea. Forecasting, 21, 86-93, https://doi.org/10.1175/WAF910.1.

Vukovich, F. M., 2007: Climatology of ocean features in the Gulf of Mexico using satellite remote sensing data.J. Phys. Oceanogr., 37, 689-707, https://doi.org/10.1175/JPO2989.1.

Walters, C. K., and J. A. Winkler, 2001: Airflow configurations of warm season southerly low-level wind maxima in the Great Plains. Part I: Spatial and temporal characteristics and relationship to convection. Wea. Forecasting, 16, 513-530, https://doi.org/ 10.1175/1520-0434(2001)016<0513:ACOWSS > 2.0.CO;2.

Warner, M. S., 2018: Introduction to PySPLIT: A Python Toolkit for NOAA ARL's HYSPLIT Model. Comput. Sci. Eng., 20, 47-62, https://doi.org/10.1109/MCSE.2017.3301549.

Weaver, S. J., and S. Nigam, 2008: Variability of the Great Plains low-level jet: Large-scale circulation context and hydroclimate impacts. J. Climate, 21, 1532-1551, https://doi.org/10.1175/ 2007JCLI1586.1.

_ , S. Baxter, and A. Kumar, 2012: Climatic role of North American low-level jets on U.S. regional tornado activity. J. Climate, 25, 6666-6683, https://doi.org/10.1175/JCLI-D-1100568.1.

Wernli, H., and C. Schwierz, 2006: Surface cyclones in the ERA-40 dataset (1958-2001). Part I: Novel identification method and global climatology. J. Atmos. Sci., 63, 2486-2507, https:// doi.org/10.1175/JAS3766.1.

Winschall, A., H. Sodemann, S. Pfahl, and H. Wernli, 2014: How important is intensified evaporation for Mediterranean precipitation extremes? J. Geophys. Res. Atmos., 119, 5240-5256, https://doi.org/10.1002/2013JD021175.

Zavala-Hidalgo, J., A. Parés-Sierra, and J. Ochoa, 2002: Seasonal variability of the temperature and heat fluxes in the Gulf of Mexico. Atmósfera, 15, 81-104.

Zhao, Q., and F. H. Carr, 1997: A prognostic cloud scheme for operational NWP models. Mon. Wea. Rev., 125, 1931-1953, https:// doi.org/10.1175/1520-0493(1997)125<1931:APCSFO>2.0.CO;2. 